BNL-105311-2014-IR

\title{
Calculation of Design Parameters for an Equilibrium LEU Core in the NBSR using a U7Mo Dispersion Fuel
}

\author{
A.L. Hanson \& D.J. Diamond
}

May 2014

\author{
Nuclear Science \& Technology \\ Brookhaven National Laboratory
}

\author{
National Nuclear Security Administration \\ National Institute of Standards \& Technology
}

Notice: This manuscript has been authored by employees of Brookhaven Science Associates, LLC under Contract No. DE-AC02-98CH10886 with the U.S. Department of Energy. The publisher by accepting the manuscript for publication acknowledges that the United States Government retains a non-exclusive, paid-up, irrevocable, world-wide license to publish or reproduce the published form of this manuscript, or allow others to do so, for United States Government purposes. 


\section{DISCLAIMER}

This report was prepared as an account of work sponsored by an agency of the United States Government. Neither the United States Government nor any agency thereof, nor any of their employees, nor any of their contractors, subcontractors, or their employees, makes any warranty, express or implied, or assumes any legal liability or responsibility for the accuracy, completeness, or any third party's use or the results of such use of any information, apparatus, product, or process disclosed, or represents that its use would not infringe privately owned rights. Reference herein to any specific commercial product, process, or service by trade name, trademark, manufacturer, or otherwise, does not necessarily constitute or imply its endorsement, recommendation, or favoring by the United States Government or any agency thereof or its contractors or subcontractors. The views and opinions of authors expressed herein do not necessarily state or reflect those of the United States Government or any agency thereof. 


\section{Calculation of Design Parameters for an Equilibrium LEU Core in the NBSR using a U7Mo Dispersion Fuel}

Manuscript Completed:

May 31, 2014

Prepared by:

A.L. Hanson and D.J. Diamond

Nuclear Science and Technology Department

Brookhaven National Laboratory

Upton, NY 11973

Prepared for:

National Nuclear Security Administration and

National Institute of Standards and Technology 



\begin{abstract}
A plan is being developed for the conversion of the NIST research reactor (NBSR) from highenriched uranium (HEU) fuel to low-enriched uranium (LEU) fuel. The LEU fuel may be a monolithic foil (LEUm) of U10Mo (10\% molybdenum by weight in an alloy with uranium) or a dispersion of U7Mo in aluminum (LEUd). A previous report provided neutronic calculations for the LEUm fuel and this report presents the neutronics parameters for the LEUd fuel. The neutronics parameters for the LEUd fuel are compared to those previously obtained for the present HEU fuel and the proposed LEUm fuel. The results show no significant differences between the LEUm and the LEUd other than the LEUd fuel requires slightly less uranium than the LEUm fuel due to less molybdenum being present. The calculations include kinetics parameters, reactivity coefficients, reactivity worths of control elements and abnormal configurations, and power distributions under normal operation and with misloaded fuel elements.
\end{abstract}




\section{ACKNOWLEDGEMENTS}

The authors appreciate the close cooperation with the staff at the National Institute for Standards and Technology (NIST), NIST Center for Neutron Research (NCNR). Without the support of Sean O’Kelly, J. Michael Rowe, and Robert Williams at NCNR this work would not have been possible. We also appreciate the important administrative support received from Lynda Fitz. 


\section{TABLE OF CONTENTS}

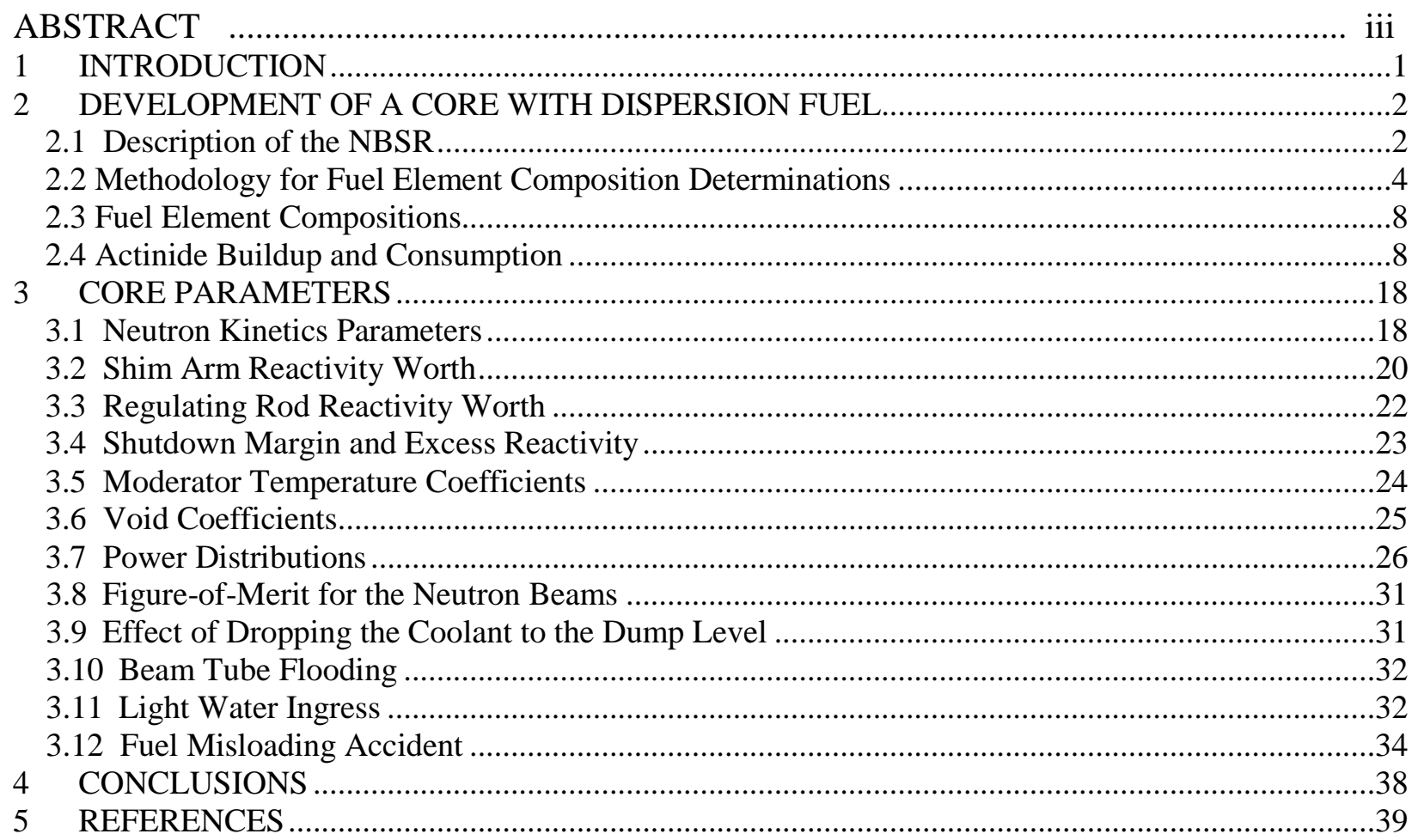




\section{LIST OF FIGURES}

Figure 2.1 Planar View at Core Midplane ................................................................................. 3

Figure 2.2 Fuel Element Position Designation ....................................................................... 3

Figure 2.3 Fuel Management Scheme ………………………............................................... 4

Figure 2.4 Flow Chart for the Methodology for Generating Inventories ........................................ 6

Figure $2.5{ }^{235} \mathrm{U}$ Content in Each Fuel Element as a Function of Cycle for HEU Fuel ..................... 8

Figure $2.6^{235} \mathrm{U}$ Content in Each Fuel Element as a Function of Cycle for LEUm Fuel ................. 9

Figure $2.7^{235} \mathrm{U}$ Content in Each Fuel Element as a Function of Cycle for LEUd Fuel .................. 9

Figure $2.8{ }^{238} \mathrm{U}$ Content in Each Fuel Element as a Function of Cycle for HEU Fuel .................... 10

Figure $2.9{ }^{238} \mathrm{U}$ Content in Each Fuel Element as a Function of Cycle for LEUm Fuel ............... 10

Figure $2.10^{238} \mathrm{U}$ Content in Each Fuel Element as a Function of Cycle for LEUd Fuel ................ 11

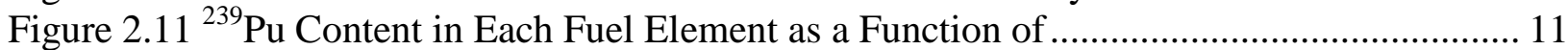

Figure $2.12{ }^{239} \mathrm{Pu}$ Content in Each Fuel Element as a Function of .............................................. 12

Figure $2.13{ }^{239} \mathrm{Pu}$ Content in Each Fuel Element as a Function of ............................................ 12

Figure 2.14 Content of all Other Actinides in Each Fuel Element as a Function.......................... 13

Figure 2.15 Content of all Other Actinides in Each Fuel Element as a Function.......................... 13

Figure 2.16 Content of all Other Actinides in Each Fuel Element as a Function.......................... 14

Figure 2.17 Grams of ${ }^{235} \mathrm{U}$ Burned per Fuel Element per cycle, for HEU Fuel. ............................ 14

Figure 2.18 Grams of ${ }^{235} \mathrm{U}$ Burned per Fuel Element per cycle, for LEUm Fuel.......................... 14

Figure 2.19 Grams of ${ }^{235} \mathrm{U}$ Burned per Fuel Element per cycle, for LEUd Fuel........................... 15

Figure 2.20 Contribution to the Power (\%) from the Fissioning of ${ }^{239} \mathrm{Pu}$ in Each Fuel Element for HEU Fuel at EOC ………………………………...................................... 15

Figure 2.21 Contribution to the Power (\%) from the Fissioning of ${ }^{239} \mathrm{Pu}$ in Each Fuel Element

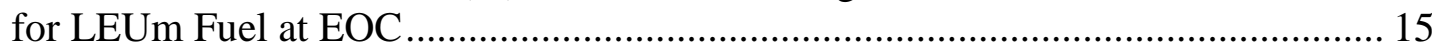

Figure 2.22 Contribution to the Power (\%) from the Fissioning of ${ }^{239} \mathrm{Pu}$ in Each Fuel Element for LEUd Fuel at EOC .......................................................................................... 16

Figure 2.23 Contribution to the Power (\%) from the Fissioning of the Other Actinides in Each Fuel Element for HEU Fuel at EOC....................................................................... 16

Figure 2.24 Contribution to the Power (\%) from the Fissioning of the Other Actinides in Each fuel Element for LEUm Fuel at EOC. .................................................................... 16

Figure 2.25 Contribution to the Power (\%) from the Fissioning of the Other Actinides in Each fuel Element for LEUd Fuel at EOC. ................................................................... 17

Figure 3.1 HEU, LEUm and LEUd Shim Arm Worths at SU...................................................... 21

Figure 3.2 HEU, LEUm and LEUd Shim Arm Worths at EOC ................................................. 21

Figure 3.3 Regulating Rod Worth at SU for HEU, LEUm, and LEUd Fuels................................. 22

Figure 3.4 Regulating Rod Worth at EOC for HEU, LEUm, and LEUd Fuels............................. 23

Figure 3.5 Radial Power Distribution for the Upper and Lower Halves of the HEU Core

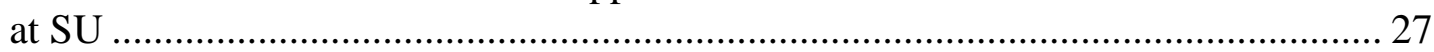

Figure 3.6 Radial Power Distribution for the Upper and Lower Halves of the LEUm Core

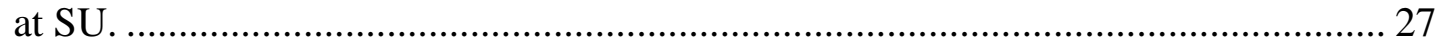

Figure 3.7 Radial Power Distribution for the Upper and Lower Halves of the LEUd Core

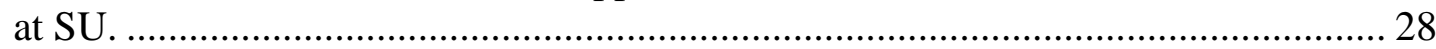

Figure 3.8 Radial Power Distribution for the Upper and Lower Halves of the HEU Core

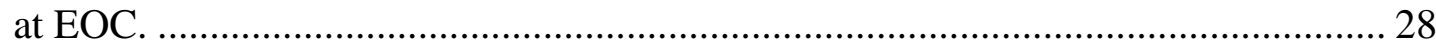

Figure 3.9 Radial Power Distribution for the Upper and Lower Halves of the LEUm Core at EOC. 
Figure 3.10 Radial Power Distribution for the Upper and Lower Halves of the LEUd Core

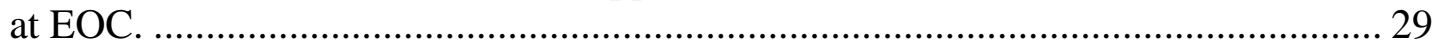

Figure 3.11 Vertical Section of the NBSR with the Coolant Dropped to the Dump Level........... 31

Figure 3.12 Effect of Light Water Ingress on the Value of $k_{\text {eff }}$ at SU ......................................... 33

Figure 3.13 Effect of Light Water Ingress on the Value of $k_{\text {eff }}$ at EOC ...................................... 33

Figure 3.14 Radial Power Distribution when the Fresh HEU Fuel Element is Placed in the

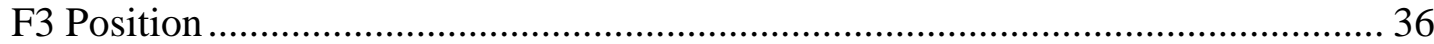

Figure 3.15 Radial Power Distribution when the Fresh LEUm Fuel Element is Placed in the

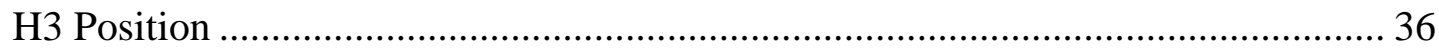

Figure 3.16 Radial Power Distribution when the Fresh LEUd Fuel Element is Placed in the H3 Position 


\section{LIST OF TABLES}

Table 2.1 Fuel Specifications per Fuel Element ............................................................... 7

Table 2.2 Effect of 1\% Mo Variation on the Fresh Fuel Composition (in grams) ....................... 7

Table 3.1 Neutron Lifetime ( $\mu$ s) Calculated using the Adjoint Flux Weighting Method............ 18

Table 3.2 Delayed Neutron Group Characteristics ................................................................ 19

Table 3.3 Percentage of Fissions from the Major Actinides...................................................... 20

Table 3.4 Total Shim Arm Worth $(\% \Delta \mathrm{k} / \mathrm{k})$ for the HEU, LEUm, and LEUd Fuels. ................... 21

Table 3.5 Total Regulating Rod Arm Worth $(\% \Delta \mathrm{k} / \mathrm{k})$ for the HEU, LEUm and LEUd Fuels..... 23

Table 3.6 Shutdown Margin and Excess Reactivity $(\% \Delta \mathrm{k} / \mathrm{k})$ for the HEU, LEUm, and LEUd

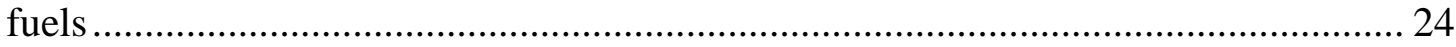

Table 3.7 Moderator Temperature Coefficient $\left(\% \Delta \mathrm{k} / \mathrm{k} /{ }^{\circ} \mathrm{C}\right)$ for HEU and LEU Fuels ................. 25

Table 3.8 Void Coefficients $(\% \Delta \mathrm{k} / \mathrm{k} /$ liter) for Voiding Specific Areas in the Core..................... 26

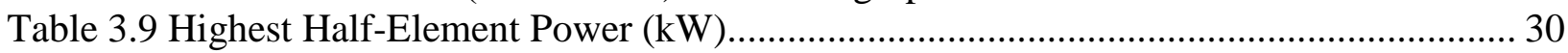

Table 3.10 Power (MW) Generated by the Inner Plenum FEs ............................................... 30

Table 3.11 Power (MW) Generated in the Upper Half vs. the Lower Half................................ 30

Table 3.12 Value of $\mathrm{k}_{\mathrm{eff}}$ when the Coolant is Lowered to the Dump Level ............................... 32

Table 3.13 Reactivity Insertion $(\% \Delta \mathrm{k} / \mathrm{k})$ from Flooding the Beam Tubes .................................. 32

Table 3.14 Maximum Relative Power (RP) in the Lower Half-Element for a Misloaded FE

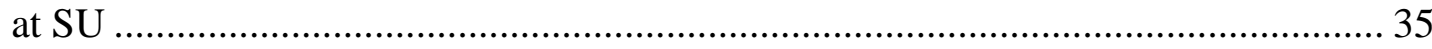




\section{INTRODUCTION}

The conversion of the NIST research reactor (NBSR) from high-enriched uranium (HEU) to low-enriched uranium (LEU) fuel necessitates a redesign of the reactor fuel. The change will occur only in the composition and thickness of the fuel meat

and the thickness of the aluminum cladding. The overall geometry of the fuel plates and the fuel elements will remain as in the present HEU core. The new fuel could be a monolithic foil of U10Mo (LEUm), a uranium alloy with 10\% molybdenum by weight or a dispersion of U7Mo mixed with aluminum. Analyses have been performed for the U10Mo fuel to determine the thickness of the foils in the fuel plates and neutronic parameters for an equilibrium LEUm core [1]. Those calculations led to a specific foil thickness and fuel plate loading that would support a 38.5-day equilibrium fuel cycle, with the shim arms completely withdrawn at the end of the cycle. This is a fundamental requirement for the converted core. The present study provides the same parameters if the fuel were to be a U7Mo dispersion fuel (LEUd). The results for the dispersion fuel are compared to the results for both the LEUm and the HEU fuels. The analysis was carried out with the same methodology that had been shown to be valid for the HEU core [1].

The objective of the current study is to analyze the potential of the dispersion LEU U7Mo fuel versus the monolithic form so that either can be considered when a down-select between the two fuels is made. Examples of these parameters are power distribution, shim arm worth, and reactivity coefficients, as well as the figure-of-merit for providing neutrons to experimenters.

The development of the dispersion fuel model subsequently used for the Monte Carlo neutronics calculations is explained in Section 2. This includes a description of the core, the methodology used to obtain the composition of each fuel element in an equilibrium core, and the resulting compositions. Section 3 provides neutronic parameters for the equilibrium LEUd core along with comparisons with the HEU and LEUm core parameters obtained previously with the same methodology. This includes results for kinetics parameters, reactivity parameters, power distributions, and neutron beam performance. References are found in Section 5. 


\section{DEVELOPMENT OF A CORE WITH DISPERSION FUEL}

\subsection{Description of the NBSR}

Presently the NBSR is fueled with HEU; the enrichment being a nominal 93\%. The fuel is $\mathrm{U}_{3} \mathrm{O}_{8}$ in an aluminum dispersion clad in aluminum (Alloy 6061). Since the reactor is cooled and moderated with $\mathrm{D}_{2} \mathrm{O}$, the fuel elements can be placed in a "loose" configuration, i.e. with significant space between each fuel element. Each fuel element has a 7-inch axial gap at the midplane. This arrangement allows for the beam tubes to point directly to the middle of the core while having no direct line-of-sight with the fuel.

Each fuel element is constructed of 17 plates in each upper and lower half (34 plates per fuel element) and is constructed in the MTR curved plate geometry. Each plate is 13 inches long with 11 inches of fuel. The thickness of fuel in each plate is 0.02 inch, equivalent to a volume of $296 \mathrm{~cm}^{3}\left(18.1 \mathrm{in}^{3}\right)$ of fuel per fuel element. This results in each fuel element having 350 grams of ${ }^{235} \mathrm{U}$. The aluminum cladding is 0.015 inch thick on each side.

Figure 2.1 shows a planar view of the NBSR at the core midplane with some of the key structures identified. North and south are top and bottom of the page, east to the right and west to the left. The new cold neutron source (CNS) in beam tube \#9 is shown as well as the CNS that has been in service for many years. There are four cadmium shim arms that are rotated through the core in a semaphore fashion. Two pivot from the east and two pivot from the west. At the end of the fuel cycle, they are fully withdrawn from the core in a horizontal position and at shutdown they are inserted at an angle of $41^{\circ}$ from horizontal.

In the startup position, the shim arms are partially inserted in the top half of the core and are slowly removed from the core during a cycle. This causes an asymmetry in the uranium burn between the top and bottom halves of the core. There is also an asymmetry between the east and west halves of the core due to asymmetries external to the core along with the semaphore motion of the shim arms. With thirty fuel elements in the NBSR, a model with 60 different materials allows each half fuel element to have its own inventory (fuel composition) and no symmetry is forced across the core. This model with 60 different materials imposes the assumption that the inventory is uniformly distributed within each material (half fuel element).

Figure 2.2 shows how the positions in the NBSR core are identified. The positions have 13 lettered columns and seven numbered rows. The space denoted with $<\mathrm{RR}>$ is the position of the regulating rod and the six positions denoted with $<>$ are the $3 \frac{1}{2}$-inch in-core irradiation thimbles. These thimbles are aluminum tubes assumed to be filled with $\mathrm{D}_{2} \mathrm{O}$ only. The four $2 \frac{1}{2}$-inch incore irradiation thimbles located in positions D4, G3, G5, and J4 are not included in Figure 2.2, but are included in the neutronics model as evidenced in Figure 2.1. There is $\sim 6.2$ inches of spacing between the rows and 3.6 inches between the columns.

The fuel management scheme for the NBSR is shown in Figure 2.3. Each fuel position is identified with two numbers and one letter. The letters are either $\mathrm{E}$ or $\mathrm{W}$ for the east or west side of the core noting that a fuel element always stays in the east side or in the west side of the core. 


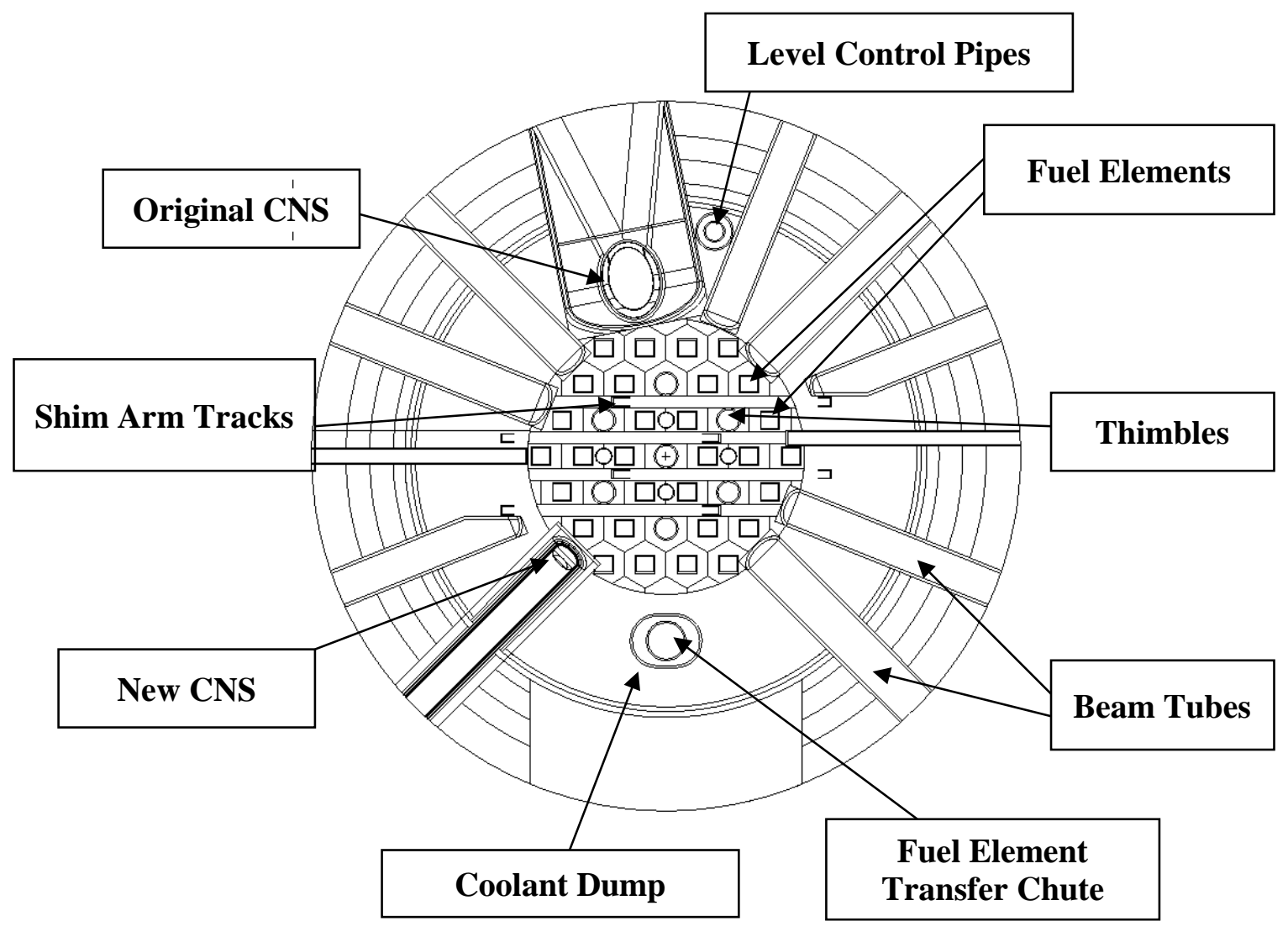

Figure 2.1 Planar View at Core Midplane

\begin{tabular}{|c|c|c|c|c|c|c|c|c|c|c|c|}
\hline & & & COI & 504 & & & & & & & \\
\hline & & & D1 & & F1 & & H1 & & $\mathrm{J} 1$ & & \\
\hline & & C2 & & E2 & & $<>$ & & I2 & & K2 & \\
\hline & B3 & & $<>$ & & F3 & & H3 & & $<>$ & & L3 \\
\hline A4 & & C4 & & E4 & & $<>$ & & I4 & & K4 & \\
\hline & B5 & & $<>$ & & F5 & & H5 & & $<>$ & & L5 \\
\hline & & C6 & D7 & E6 & F7 & $<\mathrm{RR}>$ & H7 & I6 & $\mathrm{J} 7$ & K6 & \\
\hline
\end{tabular}

Figure 2.2 Fuel Element Position Designation

Since there are thirty fuel elements, 16 stay in the core for eight cycles and 14 stay in the core for seven cycles. The first number denotes how many cycles the element will be in the core (either eight or seven) and the second number denotes the cycle in which the fuel element resides. Therefore at the beginning of a cycle, the 8-1 and 7-1 fuel elements are fresh, unirradiated fuel elements, and 8-8 and 7-7 are in their final cycles and will be removed after the cycle is over. After a cycle is finished the 8-8 and 7-7 fuel elements are removed and the 8-7 elements are moved into the 8-8 positions, the 7-6 elements are moved into the 7-7 positions. Likewise the 86 and 7-5 fuel elements are moved into the 8-7 and 7-6 positions, respectively. This keeps occurring until the 8-1 and 7-1 fuel elements are moved into the 8-2 and 7-2 positions and new, unirradiated fuel is placed in the 8-1 and 7-1 positions. 


\begin{tabular}{|c|c|c|c|c|c|c|c|c|c|c|c|c|}
\hline & & & COLD & SOUR & & & & & & & & \\
\hline & & & 8-1W & & $7-2 W$ & & $7-2 E$ & & $8-1 E$ & & & \\
\hline & & 8-3W & & 7-5W & & $<>$ & & $7-5 E$ & & 8-3E & & \\
\hline & 7-3W & & $<>$ & & $8-7 \mathrm{~W}$ & & $8-7 E$ & & $<>$ & & $7-3 E$ & \\
\hline 7-1W & & 8-6W & & $7-7 \mathrm{~W}$ & & $<>$ & & $7-7 \mathrm{E}$ & & 8-6E & & $7-1 \mathrm{E}$ \\
\hline & $8-4 W$ & & $<>$ & & 8-8W & & $8-8 E$ & & $<>$ & & $8-4 \mathrm{E}$ & \\
\hline & & $7-4 W$ & & $7-6 W$ & & $<\mathrm{RR}>$ & & $7-6 E$ & & $7-4 \mathrm{E}$ & & \\
\hline & & & $8-2 W$ & & $8-5 W$ & & $8-5 E$ & & $8-2 E$ & & & \\
\hline
\end{tabular}

Figure 2.3 Fuel Management Scheme

\subsection{Methodology for Fuel Element Composition Determinations}

The methodology for determining the fuel nuclide inventories for the NBSR Safety Analysis Report (SAR) [2] is documented elsewhere [3]. That analysis was performed using the MONTEBURNS [4] program which utilizes the MCNP [5] and ORIGEN2 [6] computer codes. In recent years, the methodology for generating inventories with MONTEBURNS has been incorporated as the BURN option of MCNPX v2.6.0 [7] and some of the capabilities expanded. MCNPX makes use of the CINDER'90 [8] code instead of ORIGEN2 for solving the burnup equations. It is this methodology that has become the standard for NBSR analysis [1]. The BURN capability along with the adjoint weighting method for the calculation of the neutron lifetime and the delayed neutron fraction have been included in the latest version of MNCP, MCNP6 [9]. MCNP6 was used for the calculations presented in this report.

The analyses performed for the SAR had been shown to be valid because it satisfies the constraints imposed, namely the initial and final (fully withdrawn) measured shim arm positions give a multiplication factor $\left(\mathrm{k}_{\mathrm{eff}}\right)$ of unity, within an acceptable uncertainty. Those results have also been shown to provide shim arm reactivity worths consistent with measurements. In [1] the differences and similarities that arose from the different methodologies used for the SAR and for the present effort are quantified and discussed.

Some of the limitations that existed in the MONTEBURNS code, as discussed in [1], remain in the MCNPX code with the BURN option. The most important issue is that not every fission product can be included in the inventory. Any isotope that is not in the library of isotopes is ignored by MCNPX and MCNPX does not include any “representative” (or "lumped”) fission product to make up the difference in the mass that is "ignored." MCNPX handles this issue by reducing the mass that is tracked in each material as CINDER'90 returns an isotope that MCNPX does not recognize. Therefore, in order to generate each inventory based on the relative mass of the material, the mass of each isotope is extracted and the "missing mass" is calculated. That mass is added to the mass of ${ }^{133} \mathrm{Cs}$, as the "representative fission product". The isotope

${ }^{133}$ Cs was selected since it is a stable fission product that is produced by the fission of all fissionable atoms so it is always present in the inventories of fission products. 
It should be noted that when the ENDF/B-VI cross section libraries were used with the MONTEBURNS/MCNP codes, the unaccounted mass was reported to be $\sim 1.2 \%$ per cycle per fuel material. Using the present ENDF/B-VII libraries, which contain more cross section files for fission products, the analyses resulted in unaccounted mass of $\sim 0.13 \%$ per cycle per fuel material. The largest number of fission products that were generated for the inventories was 54 using MONTEBURNS with the ENDF/B-VI cross section files and 181 with MCNPX using the ENDF/B-VII cross section files.

The mechanics of developing inventories are given in $[1,10]$ and will not be reproduced here, though the calculational flow chart is reproduced in Figure 2.4 for reference. The inventories are developed for the equilibrium core at four different statepoints: The startup core (SU) has fresh fuel in four locations and in the irradiated fuel, all short-lived fission products such as xenon have decayed away during the period from shutdown of the previous core, whereas the beginning-of-cycle core (BOC) has short-lived neutron poisons such as xenon at their equilibrium concentrations. BOC occurs approximately 1.5 days into a new cycle. End-of-cycle is the point at which the shim arms are completely removed and a middle-of-cycle point (MID) is halfway between BOC and EOC.

The methodology for developing the equilibrium LEUm and LEUd inventories was identical to that for developing the inventories for the HEU fuel with the exception that there is a different fuel meat and different fuel and cladding thicknesses. The thickness of each fuel plate was the same for both the HEU and the LEU fuel. The LEUm is a monolithic foil and the LEUd is a dispersion whose initial mixture and density was supplied by D. Wachs [11] at INL. The result is a fuel meat that will be thinner than the present HEU dispersion, so the same fuel volume could be maintained by adding aluminum powder to the dispersion.

The inventories were calculated with the MCNP geometry model of the NBSR, updated in 2010. The analysis utilized the MCNPX computer code with the BURN module using 60 materials and maintaining the 38.5 day cycle. As is implied from Figure 2.4, numerous sets of computer calculations were performed in order to determine that equilibrium was reached in the inventories for the HEU and the two LEU fuels. For the HEU fuel calculations of more than 30 cycles were performed and for the LEU fuel more than 20 cycles were calculated. Once a set of inventories has been developed, the $\mathrm{k}_{\mathrm{eff}}$ was calculated for the EOC equilibrium condition. This condition is the "base case" for the subsequent analyses since it represents the only situation that will be identical in the NBSR between the HEU and LEU cores; i.e. the shim arms and regulating rod are removed and there is no longer enough excess reactivity in the core to maintain criticality. At this point the NBSR has completed its fuel cycle and shuts down. By definition, the value of $\mathrm{k}_{\mathrm{eff}}$ is unity just before the reactor shuts down. However the calculations are not perfect so there is a bias in the calculations, which is the value of $\mathrm{k}_{\mathrm{eff}}$ that is calculated by the MCNP code. 


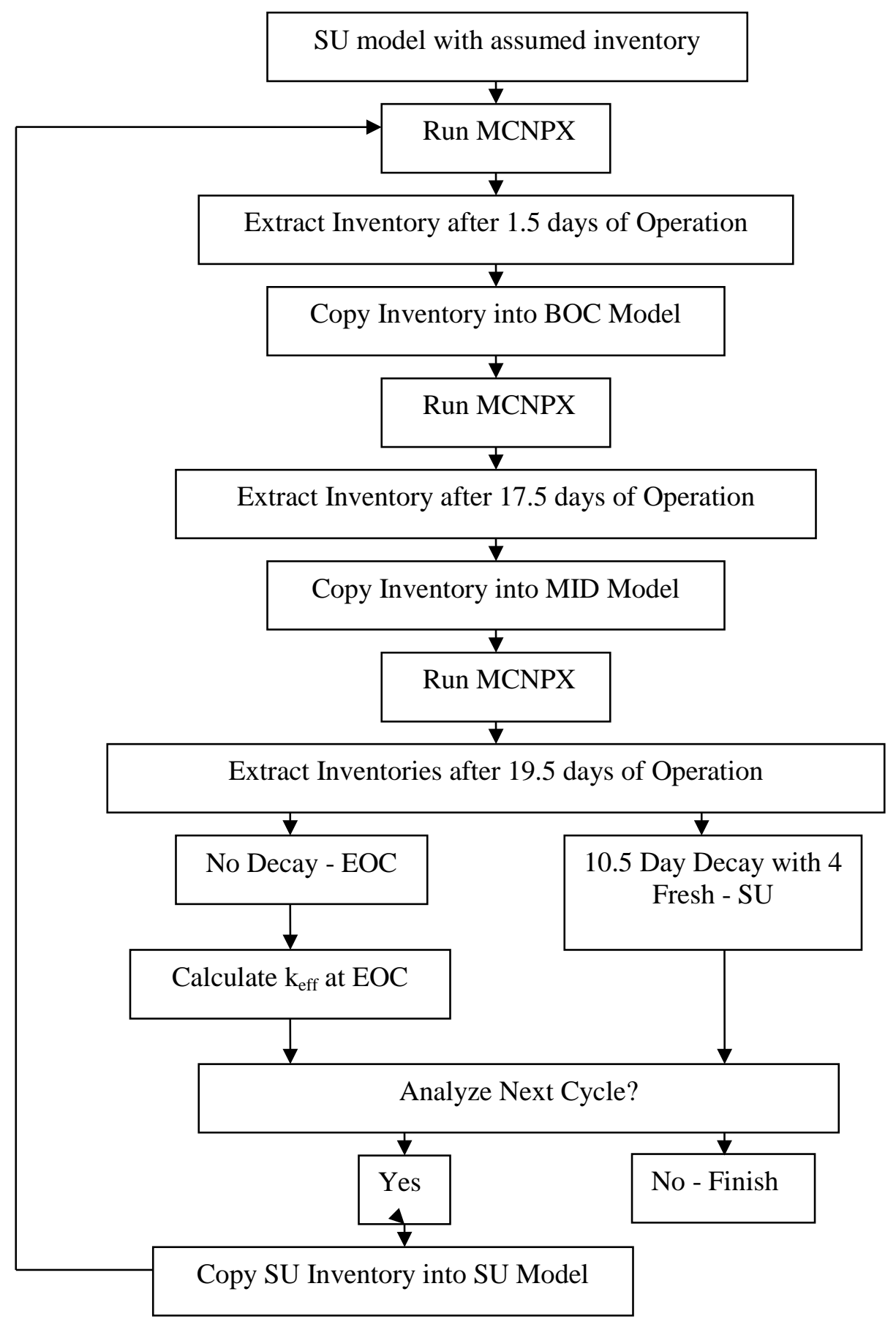

Figure 2.4 Flow Chart for the Methodology for Generating Inventories with MCNPX 
A $0.5-2 \%$ bias in MCNP calculations using the ENDFB-VII cross section libraries has been reported elsewhere [12]. For these calculations with the HEU fuel the bias is on the order of $0.6 \%$. Since the only difference between the analysis of the HEU and LEU fuels is in the composition of the fuel, we have assumed that the bias will be similar between the HEU and LEU cores. The main differences between the fuels is (1) the enrichment for the HEU fuel is $93 \%$ and for the LEU fuel is 19.75\%; (2) the HEU fuel has aluminum and oxygen in the fuel and the LEU fuels have either molybdenum or molybdenum and aluminum; (3) the cladding thickness is larger for the LEUm fuel than it is for the HEU fuel but could be the same for the LEUd fuel; (4) there are slightly more actinides in the two LEU fuels than in the HEU fuel; and (5) the LEU fuels have a small layer of zirconium (1 mil) between the fuel meat and clad. As will be discussed below, the power from the fission of ${ }^{235} \mathrm{U}$ is $\sim 100 \%$ for the HEU fuel and $\sim 96 \%$ for the two LEU fuels. The cross section libraries that were used are identical for the analysis of the cores.

The fresh fuel mass specifications are presented in Table 2.1. From [1] the volume of the LEUm foil was $125.3 \mathrm{~cm}^{3}$ in each fuel element and the volume of LEUd fuel will be $240.1 \mathrm{~cm}^{3}$. As with the uncertainty in the Mo content of the U10Mo, at this time the U7Mo is expected to also have an uncertainty in the Mo content of 1\% (range of U6Mo to U8Mo) [11]. The effects of this uncertainty on the ${ }^{235} \mathrm{U}$ and ${ }^{238} \mathrm{U}$ content is demonstrated in Table 2.2

Table 2.1 Fuel Specifications per Fuel Element

\begin{tabular}{|r|r|r|r|}
\hline & HEU & LEUm & LEUd \\
\hline${ }^{235}$ U grams & 350 & 383 & 379 \\
\hline${ }^{238}$ U grams & 26 & 1556 & 1541 \\
\hline O grams & 68 & 0 & 0 \\
\hline Al grams & 625 & 0 & 149 \\
\hline Mo grams & 0 & 215 & 325 \\
\hline Total grams & 1069 & 2154 & 2394 \\
\hline & & & \\
\hline Fuel density $\left(\mathrm{g} / \mathrm{cm}^{3}\right)$ & 3.612 & 17.2 & 9.973 \\
\hline Fuel thickness $\left(\mathrm{cm}^{3}\right)$ & 0.0508 & 0.02150 & 0.0412 \\
\hline Fuel volume $\left(\mathrm{cm}^{3}\right)$ & 296 & 125.282 & 240.1 \\
\hline
\end{tabular}

Table 2.2 Effect of 1\% Mo Variation on the Fresh Fuel Composition (in grams)

\begin{tabular}{|r|c|c|}
\hline & LEUm & LEUd \\
\hline${ }^{235} \mathrm{U}$ & $387-379$ & $382-376$ \\
\hline${ }^{238} \mathrm{U}$ & $1573-1538$ & $1553-1529$ \\
\hline $\mathrm{Mo}$ & $194-237$ & $134-164$ \\
\hline $\mathrm{Al}$ & & $325-325$ \\
\hline Total & 2154 & 2394 \\
\hline
\end{tabular}




\subsection{Fuel Element Compositions}

The total ${ }^{235} \mathrm{U}$ content of the fuel elements as a function of cycle is shown in Figures 2.5, 2.6, and 2.7 for the HEU and LEUm and LEUd fuel elements, respectively. Cycle "0" represents the fresh, unirradiated fuel. Cycle " 1 " then represents the amount of ${ }^{235} \mathrm{U}$ present in the fuel at the end of the first cycle, and so forth. Figures 2.8, 2.9 and 2.10 are the grams of ${ }^{238} \mathrm{U}$ in the fuel elements for the HEU, LEUm, and LEUd fuels, respectively, and Figures 2.11, 2.12 and 2.13 are the grams of ${ }^{239} \mathrm{Pu}$ in the fuel elements for the HEU, LEUm and LEUd fuels, respectively. Finally Figures 2.14, 2.15, and 2.16 show the amount of the other actinides in each fuel element as a function of cycle. The dominant isotope in the "other actinide" category is ${ }^{236} \mathrm{U}$. These curves indicate there is little difference between the LEUm and LEUd fuels.

\subsection{Actinide Buildup and Consumption}

Figures 2.17, 2.18 and 2.19 show the amount (in grams) of ${ }^{235} \mathrm{U}$ burned in each fuel element during each cycle for the HEU, LEUm, and the LEUd fuels, respectively. The total ${ }^{235} \mathrm{U}$ burned in a cycle is calculated to be 954 grams for the HEU fuel and 919 grams for both the LEUm fuel and for the LEUd fuels. The reason for the difference in the amount of ${ }^{235} \mathrm{U}$ burned between the HEU and two LEU fuels is due to the burning of other actinides that build up in the LEU fuels. The contribution to the power from the fissioning of ${ }^{238} \mathrm{U}$ is calculated to be $0.01 \%$ in each fuel element for the HEU fuel and between $0.47 \%$ and $0.50 \%$ for both of the LEU fuels.

Figure 2.20 shows the distribution of the power contributed by ${ }^{239} \mathrm{Pu}$ (in percent of the total power generated in each fuel element) for the HEU fuel and Figures 2.21 and 2.22 show the distribution of the ${ }^{239} \mathrm{Pu}$ power contribution for the LEUm and LEUd fuels, respectively. The relative contributions to the power generation in each fuel element from the actinides other than ${ }^{235} \mathrm{U},{ }^{238} \mathrm{U}$, and ${ }^{239} \mathrm{Pu}$ are shown in Figures 2.23, 2.24 and 2.25 for the HEU LEUm, and LEUd fuels, respectively. Over the entire core the power generated from ${ }^{235} \mathrm{U}$ is calculated to be $99.7 \%$ for the HEU fuel, and $~ 96 \%$ for both the LEUm and the LEUd fuel.

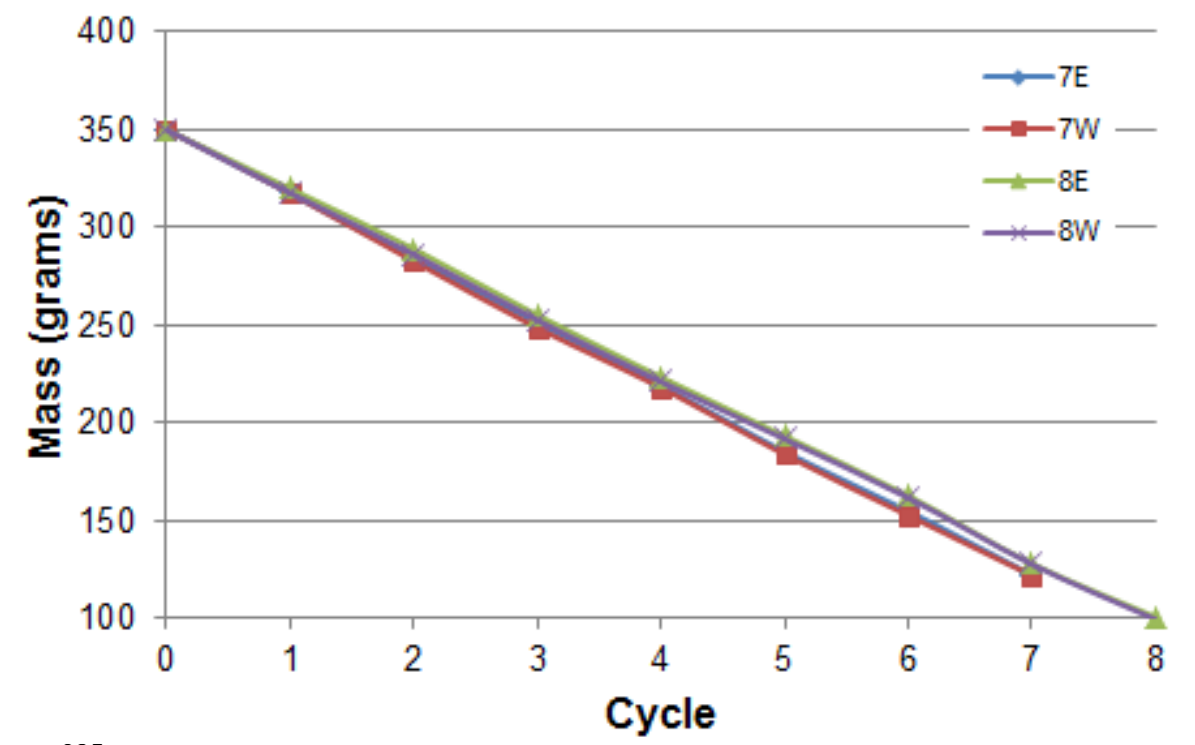

Figure $2.5{ }^{235} \mathrm{U}$ Content in Each Fuel Element as a Function of Cycle for HEU Fuel 


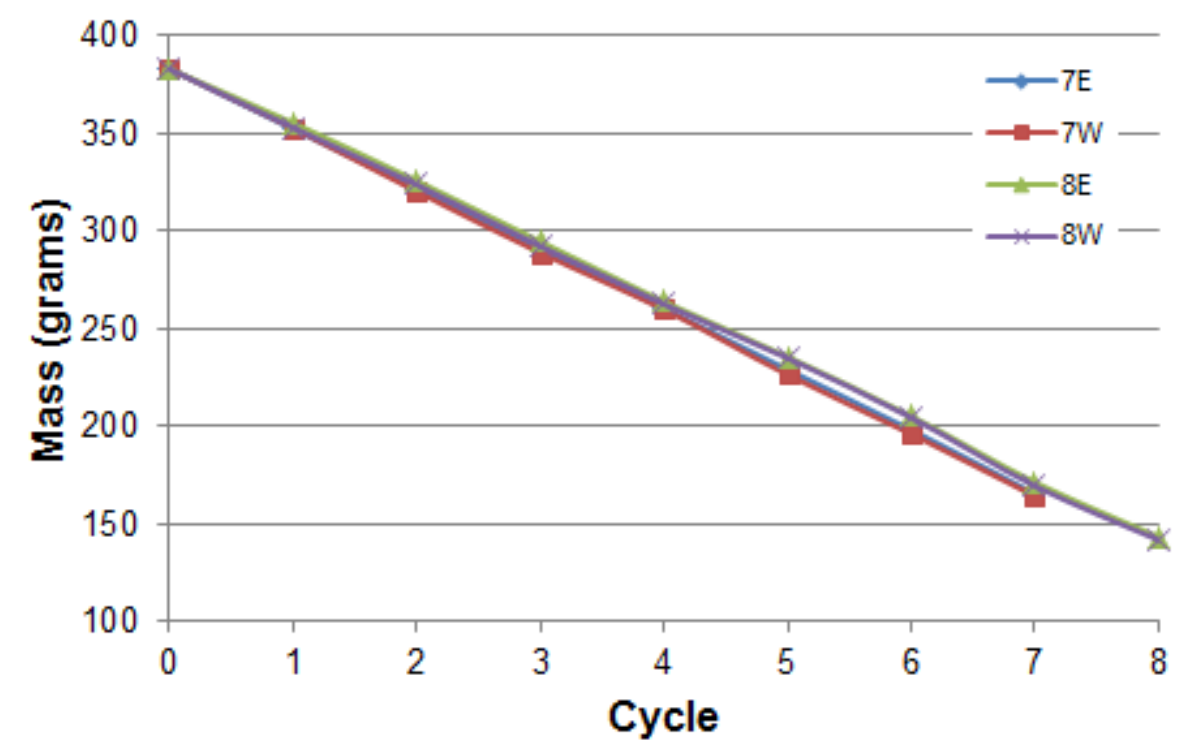

Figure $2.6{ }^{235} \mathrm{U}$ Content in Each Fuel Element as a Function of Cycle for LEUm Fuel

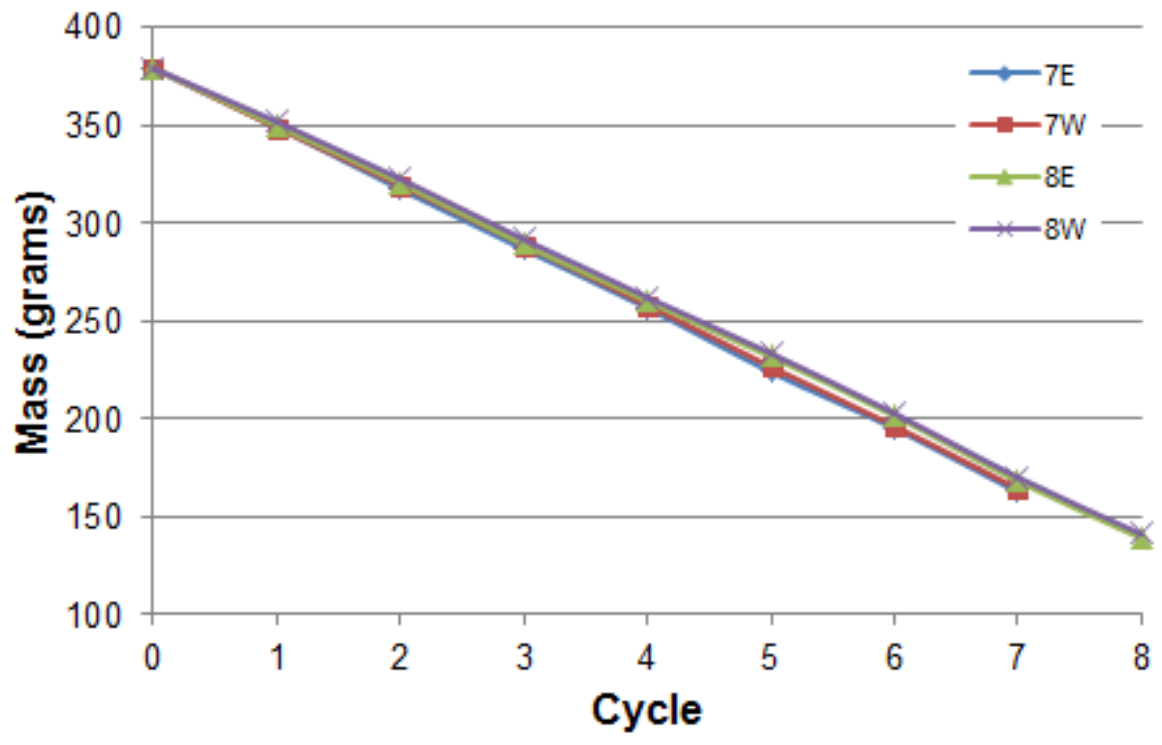

Figure $2.7^{235}$ U Content in Each Fuel Element as a Function of Cycle for LEUd Fuel 


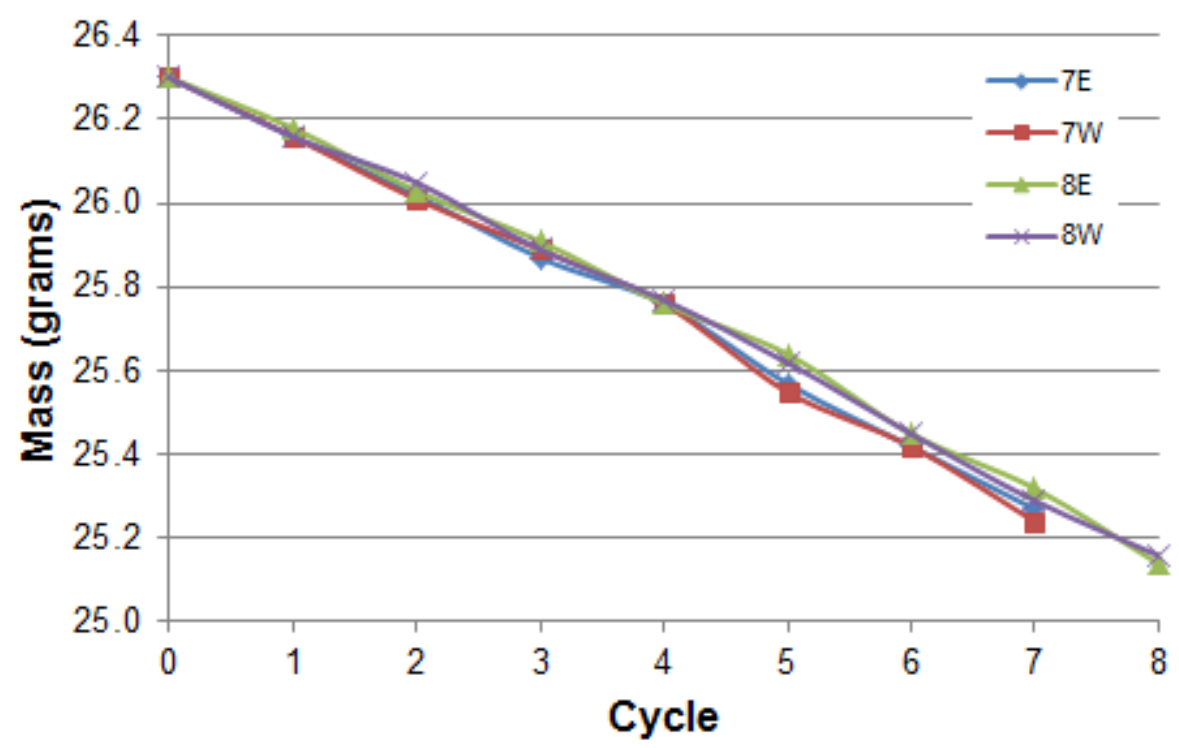

Figure $2.8{ }^{238} \mathrm{U}$ Content in Each Fuel Element as a Function of Cycle for HEU Fuel

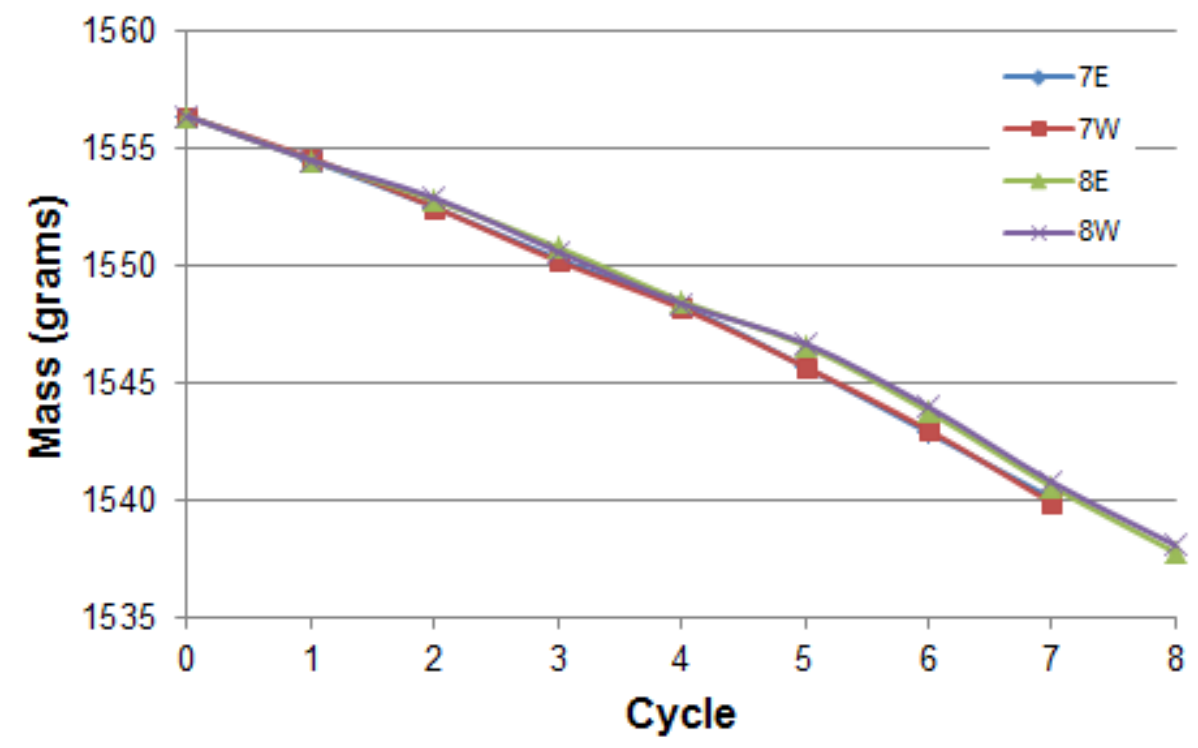

Figure $2.9{ }^{238}$ U Content in Each Fuel Element as a Function of Cycle for LEUm Fuel 


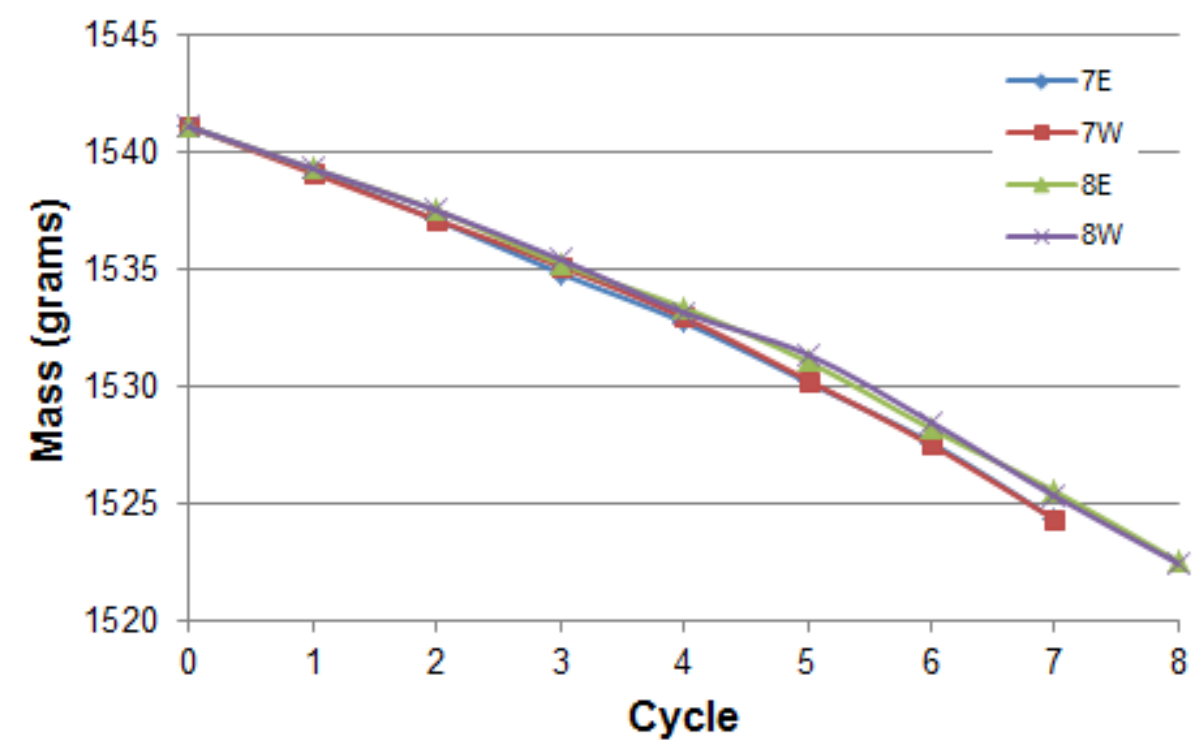

Figure $2.10{ }^{238} \mathrm{U}$ Content in Each Fuel Element as a Function of Cycle for LEUd Fuel

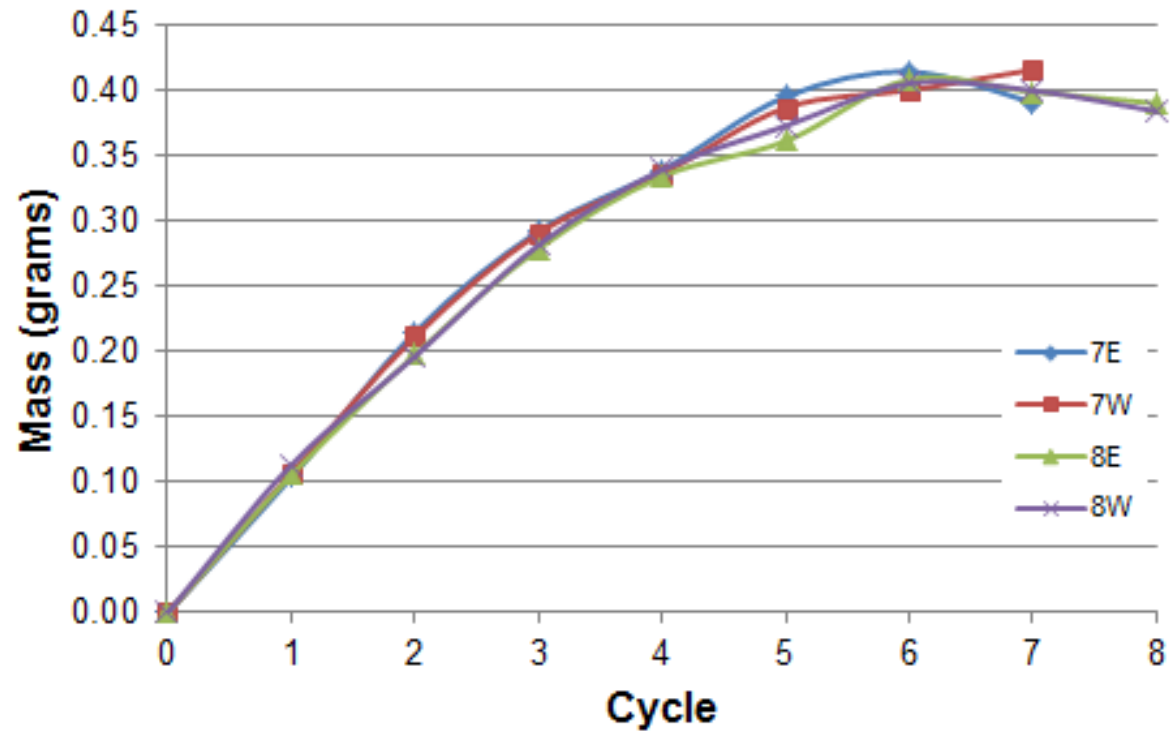

Figure $2.11{ }^{239} \mathrm{Pu}$ Content in Each Fuel Element as a Function of Cycle for HEU Fuel 


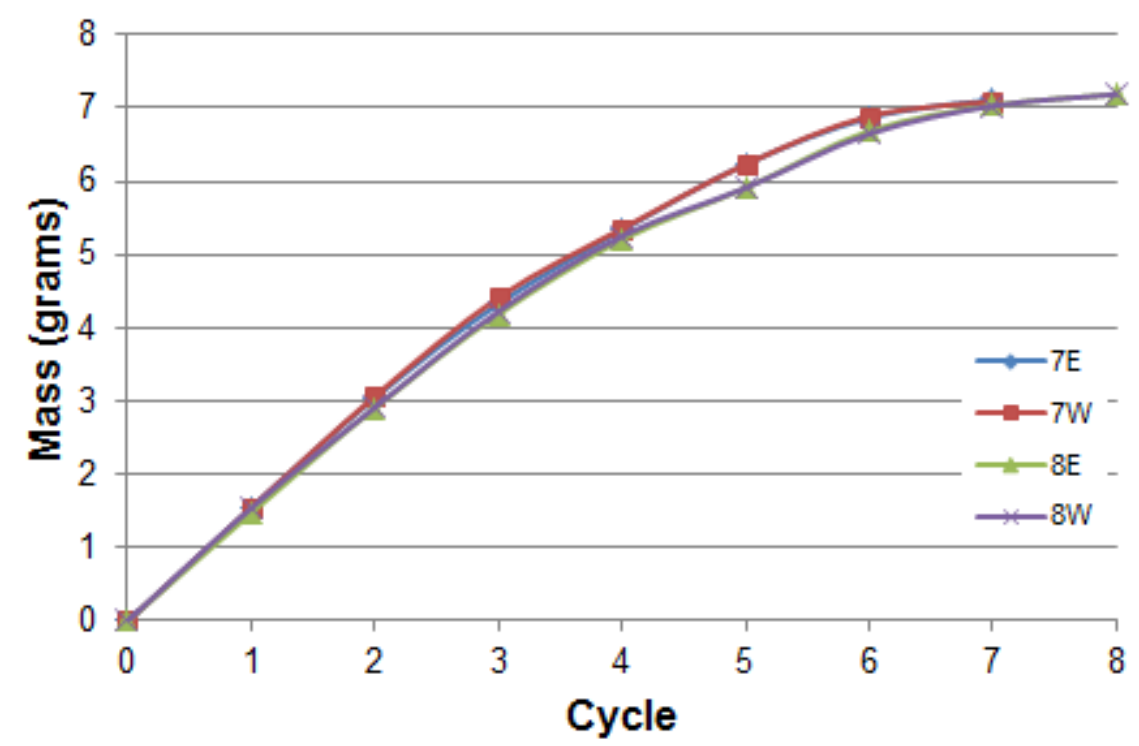

Figure 2.12 ${ }^{239} \mathrm{Pu}$ Content in Each Fuel Element as a Function of Cycle for LEUm Fuel

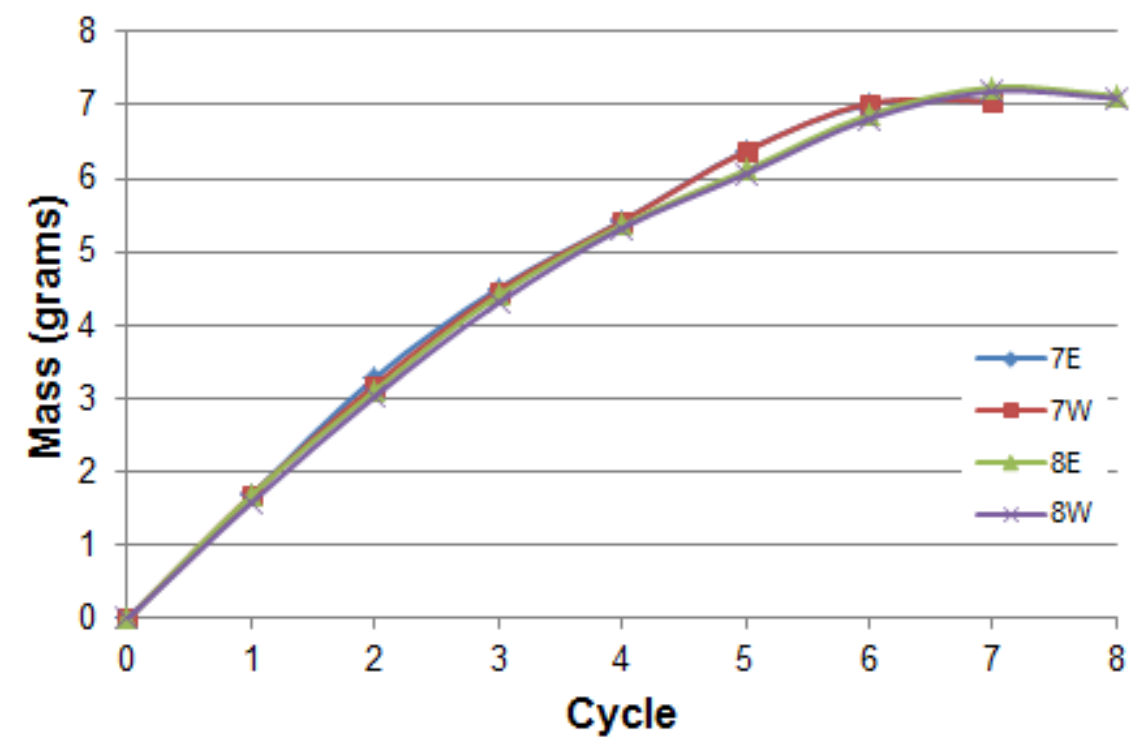

Figure $2.13{ }^{239} \mathrm{Pu}$ Content in Each Fuel Element as a Function of Cycle for LEUd Fuel 


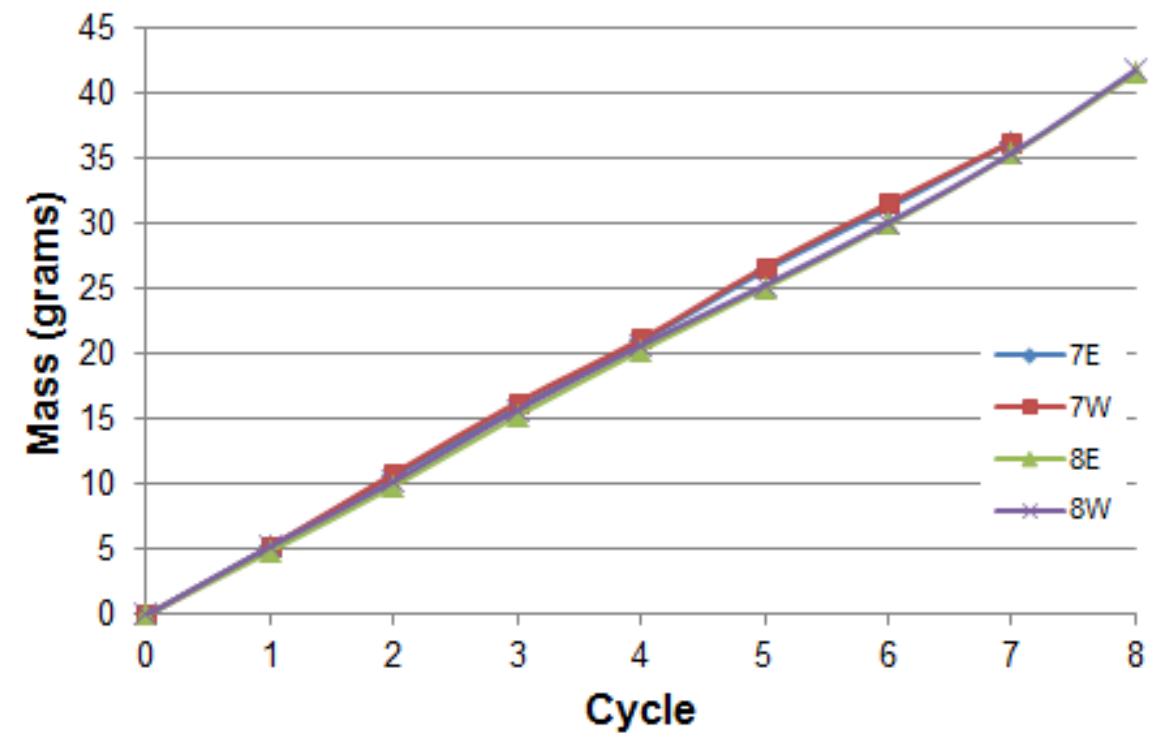

Figure 2.14 Content of all Other Actinides in Each Fuel Element as a Function of Cycle for HEU Fuel

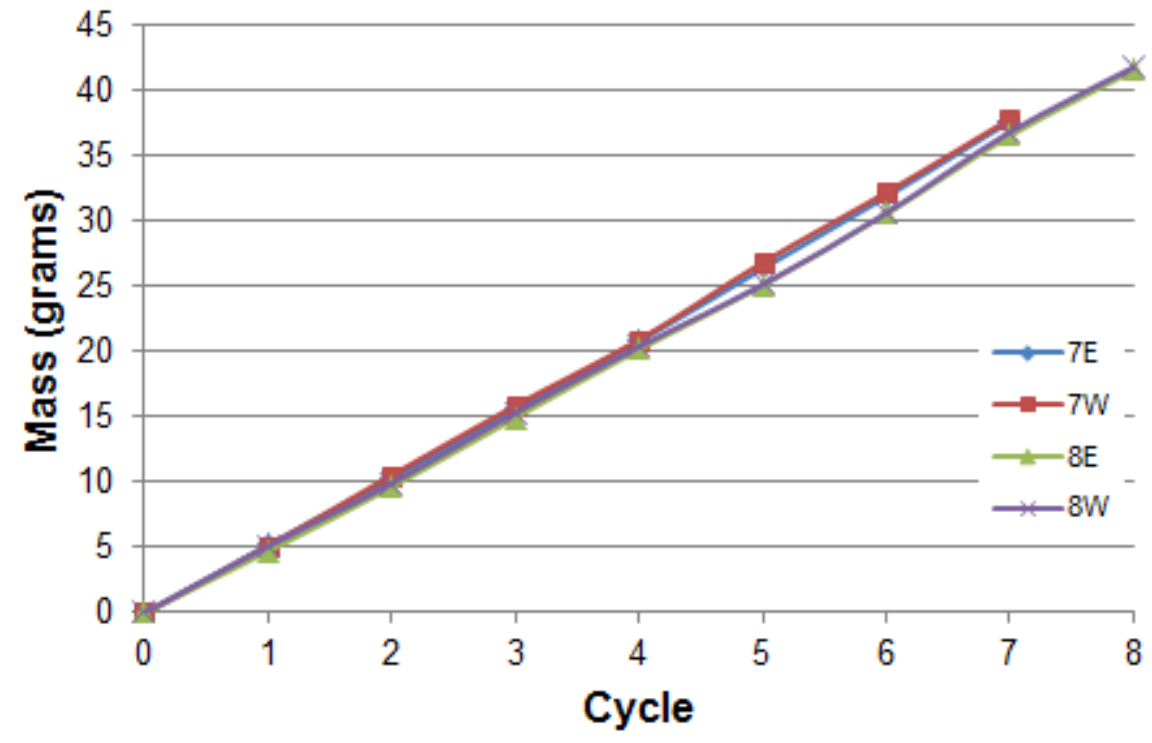

Figure 2.15 Content of all Other Actinides in Each Fuel Element as a Function of Cycle for LEUm Fuel 


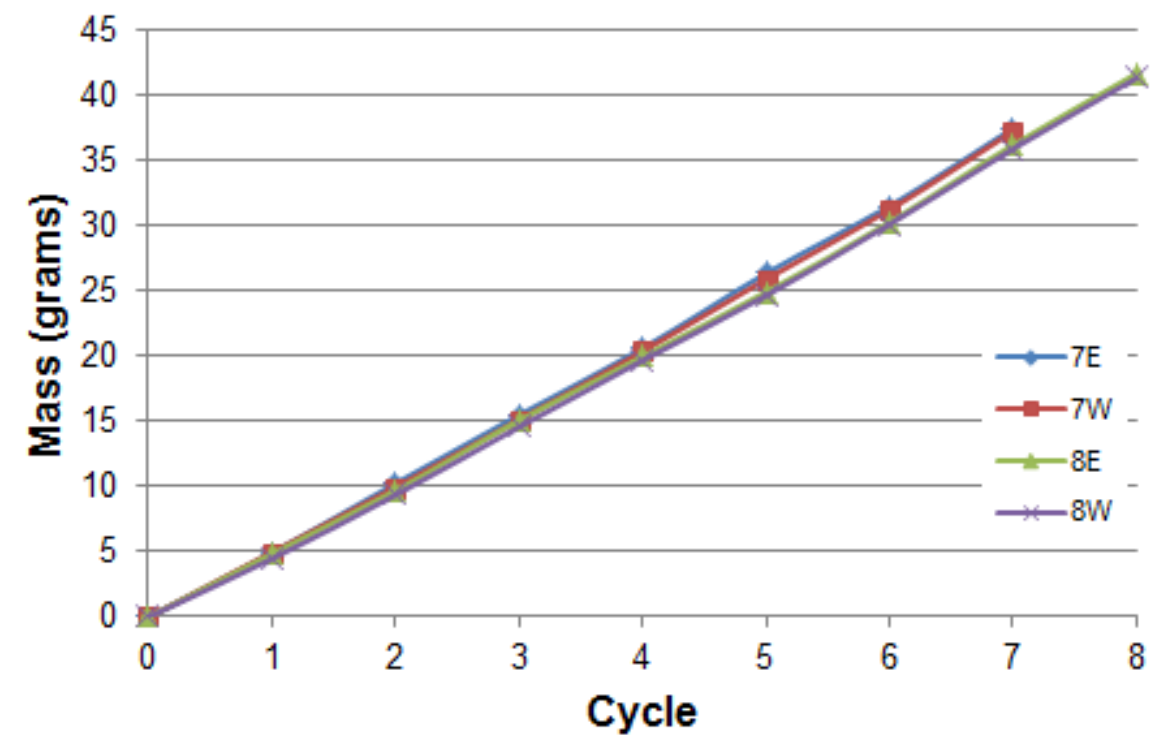

Figure 2.16 Content of all Other Actinides in Each Fuel Element as a Function of Cycle for LEUd Fuel

$\begin{array}{lllllllllllll}\text { A } & \text { B } & \text { C } & \text { D } & \text { E } & \text { F } & \text { G } & \text { H } & \text { I } & \text { J } & \text { K } & \text { L } & \text { M }\end{array}$ 1 $30.2 \quad 33.2$ $34.8 \quad 32.3$

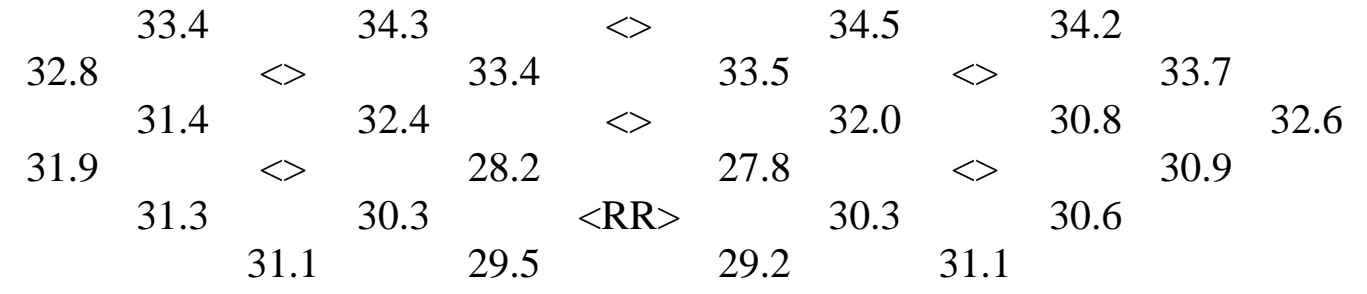

Figure 2.17 Grams of ${ }^{235} \mathrm{U}$ Burned per Fuel Element per cycle, for HEU Fuel.

$\begin{array}{lllllllllllll}\text { A } & \text { B } & \text { C } & \text { D } & \text { E } & \text { F } & \text { G } & \text { H } & \text { I } & \text { J } & \text { K } & \text { L } & \text { M }\end{array}$ COLD SOURCE

1
2
3
4
5
6
7

\begin{tabular}{|c|c|c|c|c|c|c|c|c|c|c|c|}
\hline & & 27.5 & & 30.2 & & 31.9 & & 30.7 & \multirow[b]{2}{*}{31.1} & & \\
\hline \multirow{3}{*}{31.4} & 30.9 & & 32.4 & & $<>$ & & 33.3 & & & \multirow{3}{*}{31.8} & \\
\hline & & $<>$ & & 33.8 & & 33.6 & & $<>$ & & & \\
\hline & 30.6 & & 32.5 & & $<>$ & & 32.5 & & 30.2 & & 30.7 \\
\hline 30.5 & & $<>$ & & 29.4 & & 29.1 & & $<>$ & & 28.9 & \\
\hline & 29.5 & & 30.0 & & $<\mathrm{RR}>$ & & 29.6 & 7 & 29.3 & & \\
\hline
\end{tabular}

Figure 2.18 Grams of ${ }^{235} \mathrm{U}$ Burned per Fuel Element per cycle, for LEUm Fuel NBSR Core with LEU Dispersion Fuel 
$\begin{array}{lllllllllllll}\text { A } & \text { B } & \text { C } & \text { D } & \text { E } & \text { F } & \text { G } & \text { H } & \text { I } & \text { J } & \text { K } & \text { L } & \text { M }\end{array}$

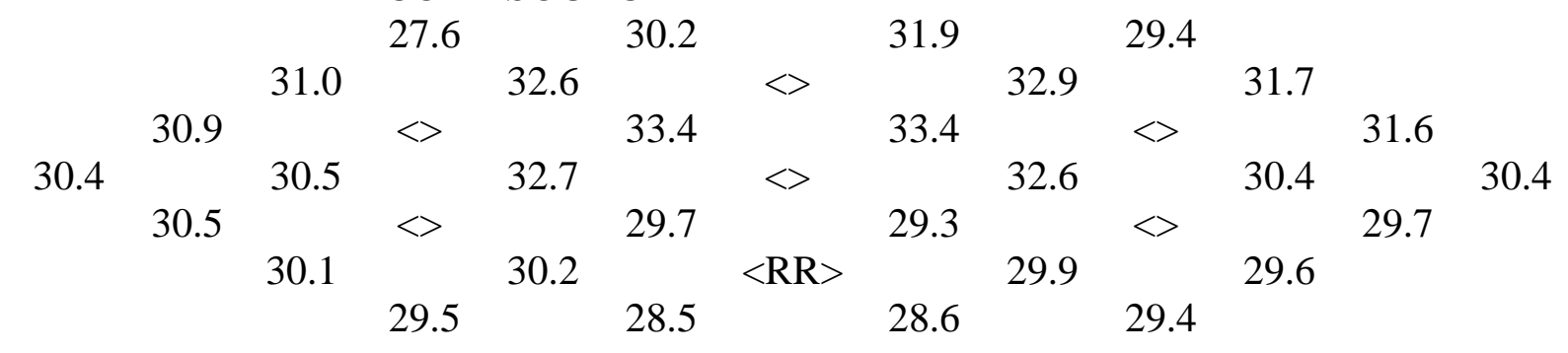

Figure 2.19 Grams of ${ }^{235} \mathrm{U}$ Burned per Fuel Element per cycle, for LEUd Fuel

\begin{tabular}{|c|c|c|c|c|c|c|c|c|c|c|c|c|}
\hline A & B & C & $\stackrel{\mathbf{D}}{\mathrm{COL}}$ & ${ }_{\mathrm{SOU}}^{\mathbf{E}}$ & $\underset{\mathrm{RCF}}{\mathbf{F}}$ & G & H & I & $\mathbf{J}$ & K & $\mathbf{L}$ & M \\
\hline 1 & & & 0.04 & & 0.11 & & 0.12 & & 0.05 & & & \\
\hline 2 & & 0.18 & & 0.34 & & $<>$ & & 0.34 & & 0.18 & & \\
\hline 3 & 0.18 & & $<>$ & & 0.50 & & 0.49 & & $<>$ & & 0.18 & \\
\hline $\begin{array}{ll}4 & 0.05\end{array}$ & & 0.40 & & 0.52 & & $<>$ & & 0.53 & & 0.41 & & 0.04 \\
\hline 5 & 0.25 & & $<>$ & & 0.59 & & 0.60 & & $<>$ & & 0.25 & \\
\hline 6 & & 0.26 & & 0.43 & & $<\mathrm{RR}>$ & & 0.44 & & 0.26 & & \\
\hline & & & 0.11 & & 0.31 & & 0.32 & & 0.11 & & & \\
\hline
\end{tabular}

Figure 2.20 Contribution to the Power (\%) from the Fissioning of ${ }^{239} \mathrm{Pu}$ in Each Fuel Element for HEU Fuel at EOC

\begin{tabular}{|c|c|c|c|c|c|c|c|c|c|c|c|c|c|}
\hline & \multirow[t]{2}{*}{ A } & B & C & D & $\mathbf{E}$ & $\mathbf{F}$ & G & H & I & $\mathbf{J}$ & $\mathbf{K}$ & $\mathbf{L}$ & $\mathbf{M}$ \\
\hline & & & & COLI & SOU & RCE & & & & & & & \\
\hline 1 & & & & 0.55 & & 1.50 & & 1.47 & & 0.58 & & & \\
\hline 2 & & & 2.28 & & 4.36 & & $<>$ & & 4.39 & & 2.32 & & \\
\hline 3 & & 2.37 & & $<>$ & & 6.24 & & 6.35 & & $<>$ & & 2.44 & \\
\hline 4 & 0.56 & & 5.14 & & 6.53 & & $<>$ & & 6.54 & & 5.16 & & 0.59 \\
\hline 5 & & 3.16 & & $<>$ & & 7.46 & & 7.49 & & $<>$ & & 3.17 & \\
\hline 6 & & & 3.29 & & 5.46 & & $<\mathrm{RR}>$ & & 5.52 & & 3.31 & & \\
\hline 7 & & & & 1.38 & & 4.00 & & 4.02 & & 1.40 & & & \\
\hline
\end{tabular}

Figure 2.21 Contribution to the Power (\%) from the Fissioning of ${ }^{239} \mathrm{Pu}$ in Each Fuel Element for LEUm Fuel at EOC 

$\begin{array}{lllllllllllll}\text { A } & \text { B } & \text { C } & \text { D } & \text { E } & \text { F } & \text { G } & \text { H } & \text { I } & \text { J } & \text { K } & \text { L } & \text { M }\end{array}$ COLD SOURCE

\begin{tabular}{|c|c|c|c|c|c|c|c|c|c|c|c|}
\hline \multirow{4}{*}{2.30} & & 0.56 & & 1.47 & & 1.47 & & 0.58 & & \multirow{4}{*}{2.34} & \\
\hline & 2.19 & & 4.20 & & $<>$ & & 4.23 & & 2.24 & & \\
\hline & & \multirow[t]{2}{*}{$<>$} & & \multirow[t]{2}{*}{6.04} & & \multirow[t]{2}{*}{6.04} & & $<>$ & & & \\
\hline & 4.92 & & 6.23 & & $<>$ & & 6.34 & & 5.00 & & 0.56 \\
\hline \multirow{2}{*}{3.04} & & \multirow[t]{2}{*}{$<>$} & & 7.19 & & 7.36 & & $<>$ & & \multirow[t]{2}{*}{3.13} & \\
\hline & 3.12 & & 5.22 & ? & $<\mathrm{RR}>$ & $? 0$ & 5.26 & 121 & 3.19 & & \\
\hline
\end{tabular}

$\begin{array}{ll}\mathbf{1} & \\ \mathbf{2} & \\ \mathbf{3} & \\ \mathbf{4} & 0.57 \\ \mathbf{5} & \\ \mathbf{6} & \\ \mathbf{7} & \end{array}$

Figure 2.22 Contribution to the Power (\%) from the Fissioning of ${ }^{239} \mathrm{Pu}$ in Each Fuel Element for LEUd Fuel at EOC

\begin{tabular}{cccccccccccccc} 
& $\mathbf{A}$ & $\mathbf{B}$ & $\mathbf{C}$ & $\mathbf{D}$ & $\mathbf{E}$ & $\mathbf{F}$ & $\mathbf{G}$ & $\mathbf{H}$ & $\mathbf{I}$ & $\mathbf{J}$ & $\mathbf{K}$ & $\mathbf{L}$ & $\mathbf{M}$ \\
& & & & \multicolumn{2}{c}{ COLD SOURCE } & & & & & & & \\
$\mathbf{1}$ & & & & 0.00 & & 0.01 & & 0.01 & & 0.00 & & & \\
$\mathbf{2}$ & & & 0.02 & & 0.05 & & $<>$ & & 0.05 & & 0.02 & & \\
$\mathbf{3}$ & & 0.02 & & $<>$ & & 0.11 & & 0.11 & & $<>$ & & 0.02 & \\
$\mathbf{4}$ & 0.00 & & 0.07 & & 0.12 & & $<>$ & & 0.12 & & 0.07 & & 0.00 \\
$\mathbf{5}$ & & 0.03 & & $<>$ & & 0.16 & & 0.16 & & $<>$ & & 0.03 & \\
$\mathbf{6}$ & & & 0.03 & & 0.08 & & $<$ RR $>$ & & 0.08 & & 0.03 & & \\
$\mathbf{7}$ & & & & 0.01 & & 0.04 & & 0.04 & & 0.01 & & &
\end{tabular}

Figure 2.23 Contribution to the Power (\%) from the Fissioning of the Other Actinides in Each Fuel Element for HEU Fuel at EOC.

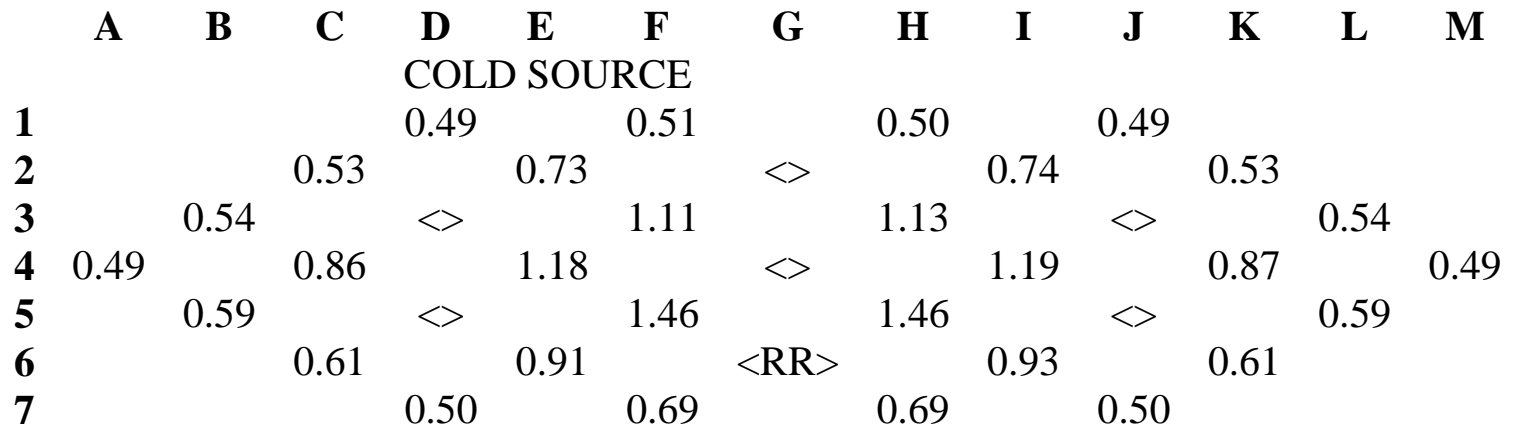

Figure 2.24 Contribution to the Power (\%) from the Fissioning of the Other Actinides in Each fuel Element for LEUm Fuel at EOC. 


\begin{tabular}{lcccccccccccccc} 
& $\mathbf{A}$ & $\mathbf{B}$ & $\mathbf{C}$ & $\mathbf{D}$ & $\mathbf{E}$ & $\mathbf{F}$ & $\mathbf{G}$ & $\mathbf{H}$ & $\mathbf{I}$ & $\mathbf{J}$ & $\mathbf{K}$ & $\mathbf{L}$ & $\mathbf{M}$ \\
$\mathbf{1}$ & & & & \multicolumn{2}{c}{ COLD SOURCE } & & & & & & & \\
$\mathbf{2}$ & & & 0.41 & & 0.79 & & 0.49 & & 0.48 & & 0.49 & & & \\
$\mathbf{3}$ & & 0.52 & & $<>$ & & 1.09 & & 1.08 & & $<>$ & & 0.53 & \\
$\mathbf{4}$ & 0.48 & & 0.83 & & 1.14 & & $<>$ & & 1.16 & & 0.84 & & 0.49 \\
$\mathbf{5}$ & & 0.57 & & $<>$ & & 1.42 & & 1.44 & & $<>$ & & 0.57 & \\
$\mathbf{6}$ & & & 0.58 & & 0.88 & & $<\mathrm{RR}>$ & & 0.90 & & 0.58 & & \\
$\mathbf{7}$ & & & & 0.48 & & 0.67 & & 0.67 & & 0.48 & & &
\end{tabular}

Figure 2.25 Contribution to the Power (\%) from the Fissioning of the Other Actinides in Each fuel Element for LEUd Fuel at EOC. 


\section{CORE PARAMETERS}

\subsection{Neutron Kinetics Parameters}

The neutron lifetime is defined as the average time between the generation of prompt fission neutrons (which does not include delayed neutrons and photoneutrons) and when they are absorbed. For a $\mathrm{D}_{2} \mathrm{O}$ cooled and moderated reactor such as the NBSR, the neutron lifetime will be longer than a reactor cooled and moderated with $\mathrm{H}_{2} \mathrm{O}$ and is typically on the order of $700 \mu$ s.

The neutron lifetime for the NBSR has been calculated with two different methods for the HEU and LEUm fuels and was reported in [1]. Only the Adjoint Flux Weighting Method as has been incorporated in MCNP [9] was used for the LEUd fuel. The results for the neutron lifetime for the HEU, LEUm, and LEUd cores at SU and EOC are provided in Table 3.1 as calculated using the Adjoint Flux Weighting method. The results for the two LEU fuels are identical. The uncertainties are based on statistics provided by MCNP.

Table 3.1 Neutron Lifetime ( $\mu$ s) Calculated using the Adjoint Flux Weighting Method.

\begin{tabular}{|c|c|c|c|c|}
\hline & SU & $\mathbf{\pm}$ & EOC & \pm \\
\hline HEU & 698 & 1 & 802 & 1 \\
\hline LEUm & 651 & 1 & 730 & 1 \\
\hline LEUd & 650 & 1 & 731 & 1 \\
\hline
\end{tabular}

The delayed neutron fraction, $\beta$, is the number of neutrons that are either emitted by fission products or are photoneutrons (the result of a $(\gamma, n)$ reaction) after the fission process has occurred, relative to the total number of neutrons emitted as a result of fission. In addition to knowing this fraction it is necessary to know the corresponding decay constant of the precursors to neutron emission. There are many neutron-rich isotopes that decay with the emission of neutrons so it is common to lump the precursors from fission products into six groups to simplify the representation with each group having an average half-life, or decay constant, $\lambda_{\mathrm{i}}$ an average fraction, $\beta_{\mathrm{i}}$ and a representative energy $\mathrm{E}_{\mathrm{i}}$ of neutron emission. Since every fissionable isotope has its own set of fission products, the mix of precursors in each group will depend on the fissionable material in the reactor and will also depend on the neutron spectra.

Several different tabulations exist that provide estimates of both the representative half-life and magnitude and the values in the tabulations can vary significantly [13]. The values calculated for delayed neutrons from fission products, using the Adjoint Flux Weighting method which was included in recent versions of MCNP, using the ENDF/B-VII cross section files, are given in Table 3.2 for the HEU, LEUm, and LEUd fuels at SU and EOC. Values of the statistical uncertainty are also provided. The values of $\beta$ are similar for the HEU and the two LEU fuels and between the SU and EOC conditions. In all cases the fraction of fissions in the NBSR is more than $95 \%$ from ${ }^{235} \mathrm{U}$ as shown in Table 3.3, for both HEU and the two LEU fuels at SU and EOC so the values of $\beta$ will be close to the values for ${ }^{235} \mathrm{U}$ alone. 
Table 3.2 Delayed Neutron Group Characteristics

\begin{tabular}{|c|c|c|c|c|c|c|}
\hline \multicolumn{7}{|c|}{ HEU Fuel at SU } \\
\hline Group & $\beta_{\mathrm{i}}$ & $\sigma$ & $\begin{array}{c}E_{\mathrm{i}} \\
(\mathrm{MeV})\end{array}$ & $\sigma$ & $\lambda_{\mathrm{i}}$ & $t_{1 / 2}$ \\
\hline 1 & 0.00022 & 0.00001 & 0.403 & 0.001 & 0.0125 & 55.5 \\
\hline 2 & 0.00111 & 0.00002 & 0.472 & 0.001 & 0.0318 & 21.8 \\
\hline 3 & 0.00107 & 0.00002 & 0.442 & 0.001 & 0.109 & 6.34 \\
\hline 4 & 0.00301 & 0.00003 & 0.557 & 0.000 & 0.317 & 2.19 \\
\hline 5 & 0.00092 & 0.00002 & 0.518 & 0.001 & 1.35 & 0.512 \\
\hline 6 & 0.00032 & 0.00001 & 0.542 & 0.002 & 8.64 & 0.0803 \\
\hline$\beta=\sum \beta_{i}$ & 0.00665 & 0.00005 & & & & \\
\hline \multicolumn{7}{|c|}{ HEU Fuel at EOC } \\
\hline Group & $\beta_{\mathrm{i}}$ & $\sigma$ & $\begin{array}{c}E_{\mathrm{i}} \\
(\mathrm{MeV})\end{array}$ & $\sigma$ & $\lambda_{\mathrm{i}}$ & $t_{1 / 2}$ \\
\hline 1 & 0.00021 & 0.00001 & 0.407 & 0.001 & 0.0125 & 55.5 \\
\hline 2 & 0.00112 & 0.00002 & 0.472 & 0.001 & 0.0318 & 21.8 \\
\hline 3 & 0.00110 & 0.00002 & 0.442 & 0.001 & 0.109 & 6.34 \\
\hline 4 & 0.00302 & 0.00003 & 0.557 & 0.000 & 0.317 & 2.19 \\
\hline 5 & 0.00087 & 0.00002 & 0.518 & 0.001 & 1.35 & 0.512 \\
\hline 6 & 0.00030 & 0.00001 & 0.539 & 0.001 & 8.64 & 0.0803 \\
\hline$\beta=\sum \beta_{i}$ & 0.00662 & 0.00005 & & & & \\
\hline \multicolumn{7}{|c|}{ LEUm Fuel at SU } \\
\hline Group & $\beta_{\mathrm{i}}$ & $\sigma$ & $\begin{array}{c}\mathrm{E}_{\mathrm{i}} \\
(\mathrm{MeV})\end{array}$ & $\sigma$ & $\lambda_{\mathrm{i}}$ & $t_{1 / 2}$ \\
\hline 1 & 0.00020 & 0.00001 & 0.405 & 0.001 & 0.0125 & 55.5 \\
\hline 2 & 0.00108 & 0.00002 & 0.473 & 0.001 & 0.0318 & 21.8 \\
\hline 3 & 0.00105 & 0.00002 & 0.442 & 0.001 & 0.109 & 6.33 \\
\hline 4 & 0.00301 & 0.00003 & 0.557 & 0.000 & 0.317 & 2.18 \\
\hline 5 & 0.00085 & 0.00002 & 0.518 & 0.001 & 1.35 & 0.513 \\
\hline 6 & 0.00030 & 0.00001 & 0.538 & 0.001 & 8.66 & 0.0801 \\
\hline$\beta=\sum \beta_{i}$ & 0.00649 & 0.00005 & & & & \\
\hline \multicolumn{7}{|c|}{ LEUm Fuel at EOC } \\
\hline Group & $\beta_{\mathrm{i}}$ & $\sigma$ & $\begin{array}{c}\mathrm{E}_{\mathrm{i}} \\
(\mathrm{MeV})\end{array}$ & $\sigma$ & $\lambda_{\mathrm{i}}$ & $t_{1 / 2}$ \\
\hline 1 & 0.00020 & 0.00001 & 0.404 & 0.001 & 0.0125 & 55.5 \\
\hline 2 & 0.00109 & 0.00002 & 0.473 & 0.001 & 0.0318 & 21.8 \\
\hline 3 & 0.00102 & 0.00002 & 0.441 & 0.001 & 0.109 & 6.33 \\
\hline 4 & 0.00301 & 0.00003 & 0.556 & 0.000 & 0.317 & 2.18 \\
\hline 5 & 0.00087 & 0.00002 & 0.517 & 0.001 & 1.35 & 0.513 \\
\hline 6 & 0.00030 & 0.00001 & 0.541 & 0.001 & 8.65 & 0.0801 \\
\hline$\beta=\sum \beta_{i}$ & 0.00649 & 0.00005 & & & & \\
\hline
\end{tabular}




\begin{tabular}{|c|c|c|c|c|c|c|}
\hline \multicolumn{7}{|c|}{ LEUd Fuel at SU } \\
\hline Group & $\beta_{\mathrm{i}}$ & $\sigma$ & $\begin{array}{c}E_{\mathrm{i}} \\
(\mathrm{MeV})\end{array}$ & $\sigma$ & $\lambda_{\mathrm{i}}$ & $t_{1 / 2}$ \\
\hline 1 & 0.0002 & 0.00001 & 0.40606 & 0.002 & 0.01249 & 55.48896 \\
\hline 2 & 0.00109 & 0.00003 & 0.47425 & 0.00089 & 0.03177 & 21.81856 \\
\hline 3 & 0.001 & 0.00003 & 0.44221 & 0.00087 & 0.10942 & 6.33454 \\
\hline 4 & 0.00292 & 0.00005 & 0.55646 & 0.0007 & 0.31731 & 2.18446 \\
\hline 5 & 0.00091 & 0.00003 & 0.51794 & 0.00134 & 1.35196 & 0.5127 \\
\hline 6 & 0.00032 & 0.00002 & 0.54392 & 0.00253 & 8.65575 & 0.08008 \\
\hline$\beta=\sum \beta_{i}$ & 0.00643 & 0.00008 & & & & \\
\hline \multicolumn{7}{|c|}{ LEUd Fuel at EOC } \\
\hline Group & $\beta_{\mathrm{i}}$ & $\sigma$ & $\begin{array}{c}E_{\mathrm{i}} \\
(\mathrm{MeV})\end{array}$ & $\sigma$ & $\overline{\lambda_{\mathrm{i}}}$ & $t_{1 / 2}$ \\
\hline 1 & 0.00022 & 0.00001 & 0.40612 & 0.00199 & 0.01249 & 55.48658 \\
\hline 2 & 0.00112 & 0.00003 & 0.47349 & 0.00089 & 0.03176 & 21.82608 \\
\hline 3 & 0.00102 & 0.00003 & 0.44159 & 0.00088 & 0.10942 & 6.3348 \\
\hline 4 & 0.00305 & 0.00005 & 0.5558 & 0.0007 & 0.31728 & 2.18465 \\
\hline 5 & 0.00086 & 0.00003 & 0.5163 & 0.00134 & 1.35127 & 0.51296 \\
\hline 6 & 0.00028 & 0.00002 & 0.54284 & 0.00253 & 8.65248 & 0.08011 \\
\hline$\beta=\sum \beta_{\mathrm{i}}$ & 0.00655 & 0.00008 & & & & \\
\hline
\end{tabular}

Table 3.3 Percentage of Fissions from the Major Actinides.

\begin{tabular}{|l|r|r|r|r|r|r|}
\hline & \multicolumn{1}{|c|}{$\begin{array}{c}\text { HEU } \\
\text { SU }\end{array}$} & \multicolumn{1}{c|}{$\begin{array}{l}\text { HEU } \\
\text { EOC }\end{array}$} & \multicolumn{1}{c|}{$\begin{array}{c}\text { LEUm } \\
\text { SU }\end{array}$} & \multicolumn{1}{c|}{$\begin{array}{c}\text { LEUm } \\
\text { EOC }\end{array}$} & \multicolumn{1}{c|}{$\begin{array}{c}\text { LEUd } \\
\text { SU }\end{array}$} & \multicolumn{1}{c|}{$\begin{array}{c}\text { LEUd } \\
\text { EOC }\end{array}$} \\
\hline${ }^{235} \mathrm{U}$ & 99.73 & 99.67 & 96.35 & 95.71 & 96.38 & 95.73 \\
\hline${ }^{236} \mathrm{U}$ & 0.02 & 0.02 & 0.02 & 0.02 & 0.01 & 0.02 \\
\hline${ }^{238} \mathrm{U}$ & 0.01 & 0.01 & 0.49 & 0.49 & 0.47 & 0.47 \\
\hline${ }^{239} \mathrm{Pu}$ & 0.23 & 0.27 & 2.99 & 3.54 & 2.97 & 3.55 \\
\hline${ }^{241} \mathrm{Pu}$ & 0.02 & 0.02 & 0.16 & 0.24 & 0.15 & 0.23 \\
\hline
\end{tabular}

\subsection{Shim Arm Reactivity Worth}

The worth of the shim arms was calculated using the fuel inventories at startup and end-of-cycle and calculating $\mathrm{k}_{\mathrm{eff}}$ as a function of shim arm position (moving all four of the shim arms together). The shim arm worth curves for the HEU and LEU fuels are shown in Figures 3.1 at SU and 3.2 at EOC. The shim arms with the LEU fuels have less total worth than the shim arms with the HEU fuel. This is demonstrated in Table 3.4, the total shim arm worth with the three fuels. 


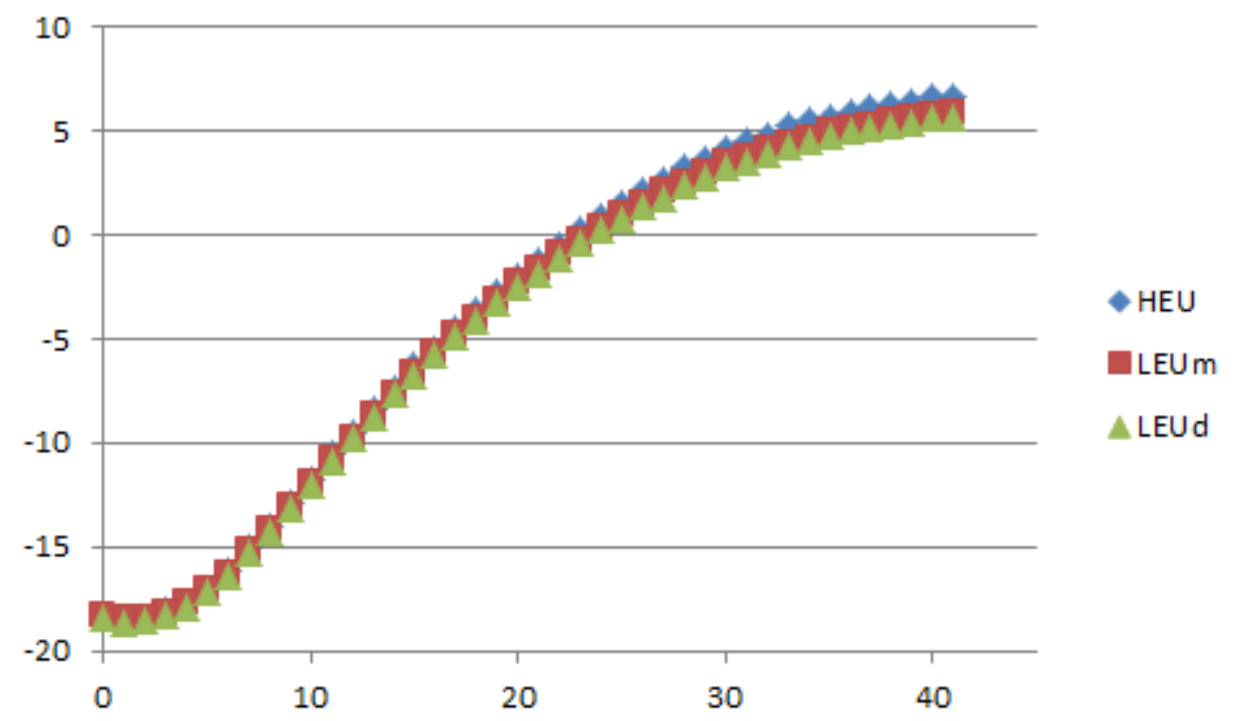

Figure 3.1 HEU, LEUm and LEUd Shim Arm Worths at SU

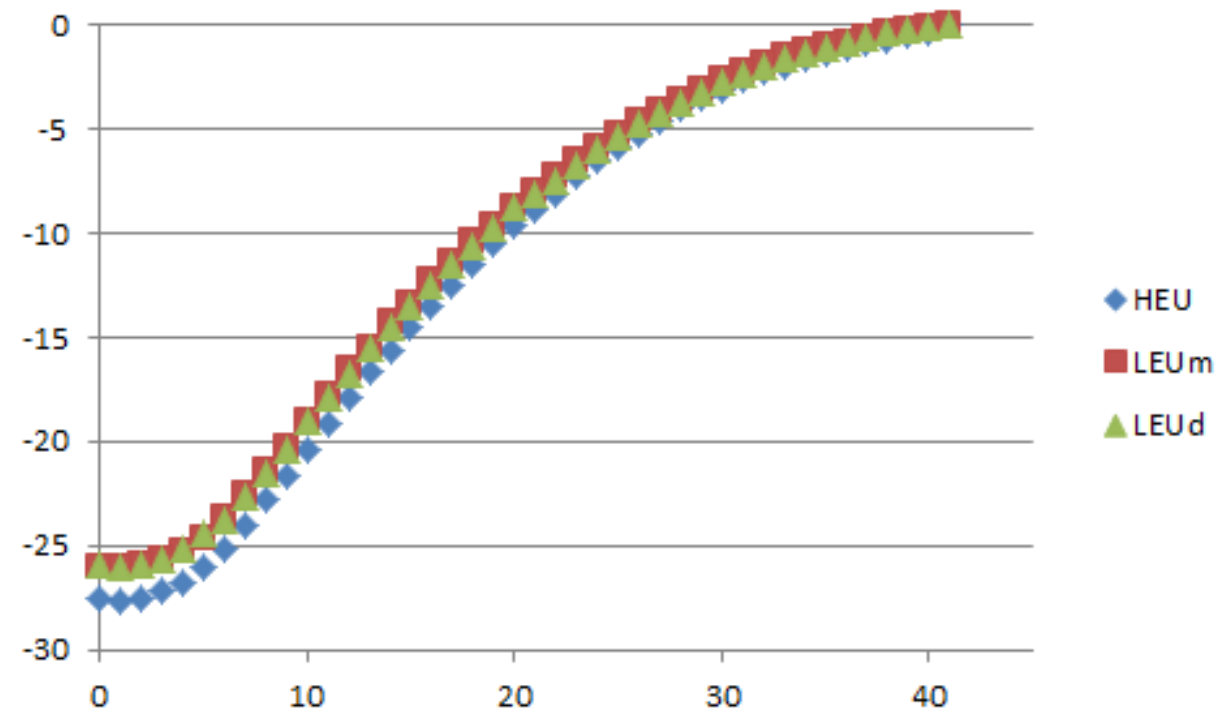

Figure 3.2 HEU, LEUm and LEUd Shim Arm Worths at EOC

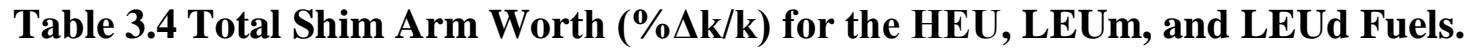

\begin{tabular}{|c|c|c|}
\hline & SU & EOC \\
\hline HEU & 24.9 & 27.2 \\
\hline LEUm & 24.2 & 26.0 \\
\hline LEUd & 24.1 & 25.8 \\
\hline
\end{tabular}




\subsection{Regulating Rod Reactivity Worth}

The regulating rod is an aluminum rod located in the G6 position. It performs the automatic fine control of the reactivity between larger reactivity insertions when the shim arms are moved. As the uranium in the core fissions, excess reactivity is lost and that loss is compensated by a slow and continuous withdrawal of the regulating rod. When the regulating rod is nearly fully withdrawn the shims arms are moved outward and the regulating rod is re-inserted. The regulating rod works by adding a large volume of a weak absorber $(\mathrm{Al})$ and displacing $\mathrm{D}_{2} \mathrm{O}$ from the G6 position in the core when it is fully inserted. The worth curves for the regulating rod are shown for the HEU and LEU fuels in Figure 3.3 at SU and Figure 3.4 at EOC. The total calculated worth is shown in Table 3.5.

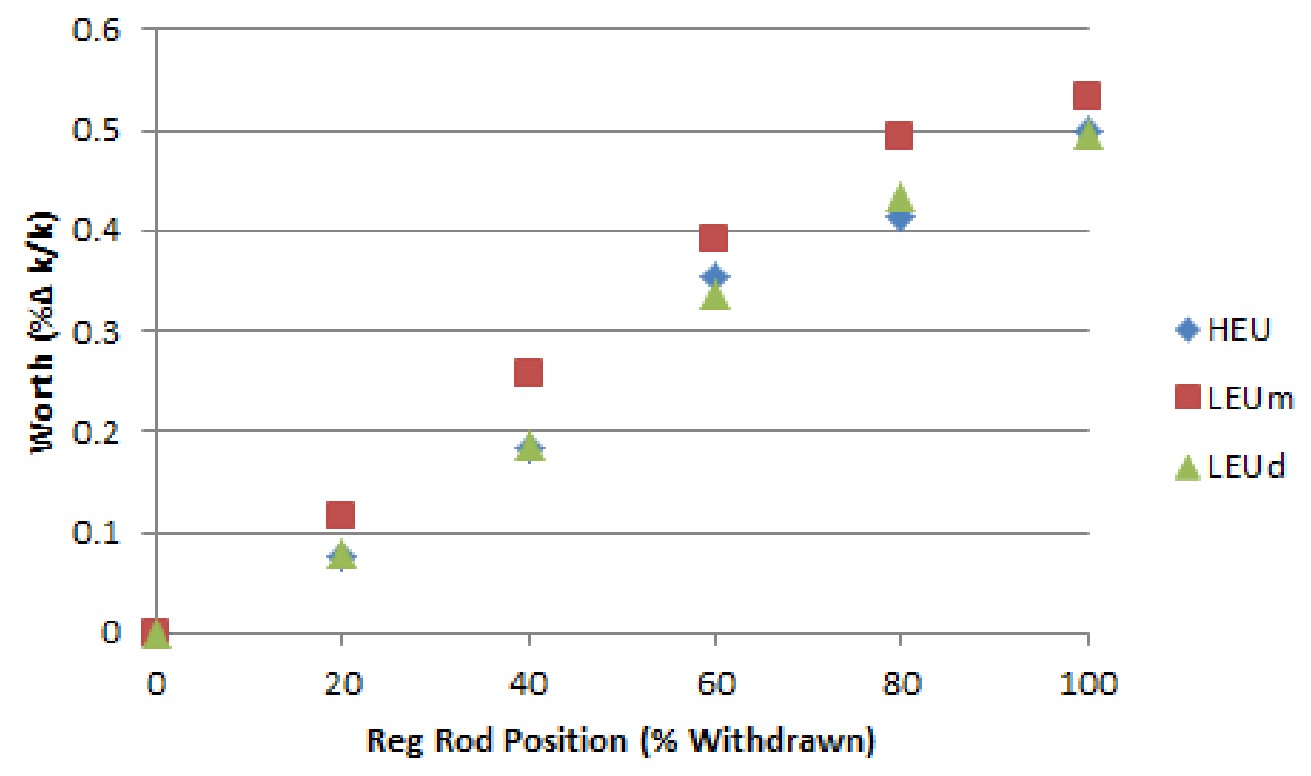

Figure 3.3 Regulating Rod Worth at SU for HEU, LEUm, and LEUd Fuels 


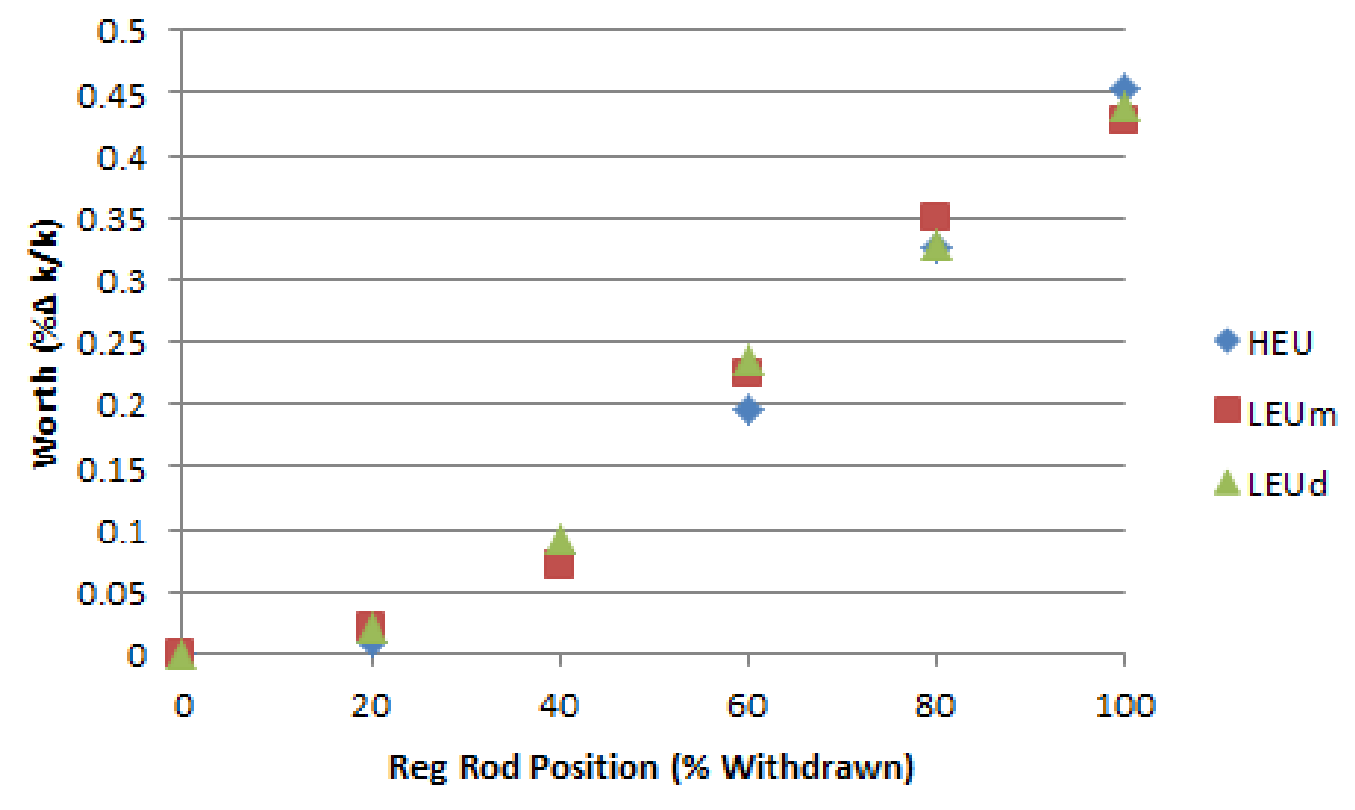

Figure 3.4 Regulating Rod Worth at EOC for HEU, LEUm, and LEUd Fuels

Table 3.5 Total Regulating Rod Arm Worth $(\% \Delta \mathrm{k} / \mathrm{k})$ for the HEU, LEUm and LEUd Fuels

\begin{tabular}{|c|c|c|}
\hline & SU & EOC \\
\hline HEU & 0.50 & 0.45 \\
\hline LEUm & 0.53 & 0.43 \\
\hline LEUd & 0.50 & 0.44 \\
\hline
\end{tabular}

\subsection{Shutdown Margin and Excess Reactivity}

NBSR Technical Specification 3.1.2, Reactivity Limitations [14], states that the core cannot be loaded such that the excess reactivity will exceed $15 \% \Delta \mathrm{k} / \mathrm{k}$ and it also states that the NBSR shall not be operated if it cannot be kept shutdown with the most reactive shim arm fully retracted. To determine if these conditions are met, $\mathrm{k}_{\text {eff }}$ was calculated under the following conditions: all shims inserted (shutdown reactivity), all shim arms withdrawn (excess reactivity), and three of the four shim arms inserted with the other withdrawn (shutdown margin). The calculations were done at the most limiting time in the cycle which is SU when the fuel is freshest and there is no ${ }^{135}$ Xe present.

The results of the calculations for each of the three fuels are shown in Table 3.6. This table demonstrates that neither the HEU nor either of the LEU equilibrium cores exceed the excess reactivity limit of $15 \% \Delta \mathrm{k} / \mathrm{k}$. This table also shows that for both the HEU and the two LEU fuels the core can be maintained in a shutdown condition with the most reactive shim arm withdrawn; shim arm \#3. Note that these calculations are for fresh (or with no significant burnup) cadmium shim arms. After 25 fuel cycles, their life expectancy, shim arm total worth has dropped $6.1 \% \Delta \mathrm{k} / \mathrm{k}[15,16]$. However, SDM is still adequate. 


\section{Table 3.6 Shutdown Margin and Excess Reactivity $(\% \Delta k / k)$ for the HEU, LEUm, and LEUd fuels}

\begin{tabular}{|l|l|r|r|r|}
\hline \multicolumn{2}{|l|}{} & \multicolumn{1}{c|}{ HEU } & \multicolumn{1}{c|}{ LEUm } & \multicolumn{1}{c|}{ LEUd } \\
\hline \multicolumn{2}{|l|}{ Shutdown reactivity (all shim arms in) } & -18.2 & -18.3 & -18.1 \\
\hline SDM & Shim 1 out & -12.1 & -12.2 & -12.1 \\
\hline SDM & Shim 2 out & -11.1 & -11.2 & -11.0 \\
\hline SDM & Shim 3 out & -10.1 & -10.8 & -10.6 \\
\hline SDM & Shim 4 out & -11.6 & -11.9 & -11.9 \\
\hline \multicolumn{2}{|l|}{ Excess reactivity (all shim arms out) } & 6.7 & 6.3 & 6.4 \\
\hline
\end{tabular}

\subsection{Moderator Temperature Coefficients}

The moderator temperature coefficient (MTC) should be negative so if there is an inadvertent power rise, and hence a heating of the moderator, there will not be a positive feedback causing a further rise in the power. MCNP handles temperature of the moderator in two ways. The first is by specifying the density of the moderator and the second is through the cross section file which provides scattering kernels at different temperatures.

The density of the $\mathrm{D}_{2} \mathrm{O}$ is a user input so it can be changed in a continuous manner in order to study the effects of moderator temperature on the performance of the NBSR. For the general MCNP model of the NBSR, the density of the $\mathrm{D}_{2} \mathrm{O}$ is $1.0977 \mathrm{~g} / \mathrm{cm}^{3}$, the density at $46^{\circ} \mathrm{C}\left(115^{\circ} \mathrm{F}\right)$.

The scattering kernel of the deuterium was selected to be $293.6 \mathrm{~K}\left(20^{\circ} \mathrm{C}\right)$. In the ENDF/B--VII cross section files the scattering kernels are in $50^{\circ} \mathrm{C}$ increments, so the next highest available scattering kernel for deuterium is for a temperature of $350 \mathrm{~K}\left(76^{\circ} \mathrm{C}\right)$. The $20^{\circ} \mathrm{C}$ scattering kernel was selected since it is closer to the actual nominal operating temperature than the $350 \mathrm{~K}$ scattering kernel.

The MTC is calculated using the two ways of representing temperature change. First the scattering kernel was changed from $293.6 \mathrm{~K}$ to $350 \mathrm{~K}$. The value of $k_{\text {eff }}$ was determined with MCNP and $\Delta \mathrm{k} / \mathrm{k}$ was calculated based on the values of $\mathrm{k}_{\text {eff }}$ at the two temperatures. $\Delta \mathrm{k} / \mathrm{k}$ was then divided by the temperature change. Second, the density was changed based on temperatures from $46^{\circ} \mathrm{C}$ to $96^{\circ} \mathrm{C}$ in $10^{\circ} \mathrm{C}$ increments maintaining the 293.6K scattering kernel. For each temperature step the value of $\mathrm{k}_{\mathrm{eff}}$ and $\Delta \mathrm{k} / \mathrm{k}$ was calculated and divided by the temperature change. The values of $\Delta \mathrm{k} / \mathrm{k} /{ }^{\circ} \mathrm{C}$ were then averaged. The values of reactivity change per degree from the scattering kernel change are added to the values calculated with the density change. The results of the calculations for the HEU and LEU fuels at SU and EOC are presented in Table 3.7. The MTC results are negative and similar for the HEU and LEU cores. 
Table 3.7 Moderator Temperature Coefficient $\left(\% \Delta \mathrm{k} / \mathrm{k} /{ }^{\circ} \mathrm{C}\right)$ for HEU and LEU Fuels at SU and EOC.

\begin{tabular}{|c|c|c|c|}
\hline \multicolumn{4}{|c|}{ SU } \\
\hline & HEU & LEUm & LEUd \\
\hline By Scattering Kernel & $-0.0083 \pm 0.0002$ & $-0.0063 \pm 0.0003$ & $-0.0054 \pm 0.0002$ \\
\hline By Density Change & $-0.0215 \pm 0.0002$ & $-0.0218 \pm 0.0003$ & $-0.0203 \pm 0.0002$ \\
\hline Total & $-0.0297 \pm 0.0003$ & $-0.0280 \pm 0.0003$ & $-0.0258 \pm 0.0002$ \\
\hline \multicolumn{4}{|c|}{ EOC } \\
\hline & HEU & LEUm & LEUd \\
\hline By Scattering Kernel & $-0.0074 \pm 0.0002$ & $-0.0045 \pm 0.0002$ & $-0.0042 \pm 0.0002$ \\
\hline By Density Change & $-0.0201 \pm 0.0002$ & $-0.0183 \pm 0.0002$ & $-0.0190 \pm 0.0002$ \\
\hline Total & $-0.0275 \pm 0.0003$ & $-0.0228 \pm 0.0003$ & $-0.0232 \pm 0.0002$ \\
\hline
\end{tabular}

\subsection{Void Coefficients}

As with the MTC, the void coefficient also needs to be negative. If a bubble forms somehow in the core (e.g., through boiling) there should be negative feedback to the power level. The formation of bubbles is modeled as a change in the density of the coolant and moderator. In the discussion of the MTC in Section 3.6 lowering the density of the moderator was shown to result in negative feedback so any process that results in the decrease in the density will likewise have negative feedback.

Creating a void within a fuel element or irradiation thimble was calculated for the following cases:

- void all 2.5-inch irradiation thimbles

- void all 3.5-inch irradiation thimbles

- void all irradiation thimbles

- void the 7-inch gap in the fuel elements (FEs)

- void all of the fuel elements within the upper and lower bounds of the fueled regions

One could create a void in an irradiation thimble by placing an experiment in the thimble, but there is probably no credible method to create any void in the fuel elements other than boiling due to flow blockage. The methodology for this analysis is similar to the methodology for calculating the MTC. The region is first voided, the reactivity change $(\Delta \mathrm{k} / \mathrm{k})$ calculated, and the reactivity change divided by the volume of the void. The results are presented in Table 3.8 in $\% \Delta \mathrm{k} / \mathrm{k} /$ liter for the HEU and LEU cores at SU and EOC. The results in Table 3.8 demonstrate that a void forming anywhere within the NBSR is expected to provide negative reactivity feedback. The magnitude of the feedback is similar for the HEU and the two LEU cores. 
Table 3.8 Void Coefficients $(\% \Delta \mathrm{k} / \mathbf{k} /$ liter) for Voiding Specific Areas in the Core.

\begin{tabular}{|l|l|l|l|}
\hline \multicolumn{1}{|c|}{ SU } & HEU & LEUm & LEUd \\
\hline \multicolumn{1}{|c|}{} & & & \\
\hline Four 2.5-in thimbles voided & $-0.045 \pm 0.002$ & $-0.044 \pm 0.002$ & $-0.045 \pm 0.001$ \\
\hline Six 3.5-in thimbles voided & $-0.036 \pm 0.001$ & $-0.037 \pm 0.001$ & $-0.038 \pm 0.001$ \\
\hline All thimbles voided & $-0.038 \pm 0.001$ & $-0.039 \pm 0.001$ & $-0.039 \pm 0.001$ \\
\hline All FE gaps voided & $-0.027 \pm 0.001$ & $-0.031 \pm 0.002$ & $-0.029 \pm 0.001$ \\
\hline All FEs voided & $-0.019 \pm 0.001$ & $-0.018 \pm 0.001$ & $-0.018 \pm 0.001$ \\
\hline \multicolumn{1}{|c|}{ EOC } & & & \\
\hline Four 2.5-in thimbles voided & $-0.034 \pm 0.001$ & $-0.035 \pm 0.001$ & $-0.027 \pm 0.001$ \\
\hline Six 3.5-in thimbles voided & $-0.030 \pm 0.001$ & $-0.032 \pm 0.001$ & $-0.028 \pm 0.001$ \\
\hline All thimbles voided & $-0.031 \pm 0.001$ & $-0.032 \pm 0.001$ & $-0.030 \pm 0.001$ \\
\hline All FE gaps voided & $-0.022 \pm 0.001$ & $-0.023 \pm 0.001$ & $-0.016 \pm 0.001$ \\
\hline All FEs voided & $-0.022 \pm 0.001$ & $-0.022 \pm 0.001$ & $-0.020 \pm 0.001$ \\
\hline & & & \\
\hline
\end{tabular}

\subsection{Power Distributions}

The radial power distributions show the average power generated in each half fuel element. Figure 3.5 shows the radial power distribution for the upper and lower half cores for the HEU core at SU. The numbers are the relative power generated in each location in the core. The power distributions are normalized so that unity represents the average power in a half fuel element, i.e., $1 / 60$ of the total core power $(=1 / 3 \mathrm{MW})$. Figure 3.6 shows the radial power distribution for the upper and lower half cores for the LEUm core at SU and Figure 3.7 shows the radial power distribution for the upper and lower half cores for the LEUd core at SU. Figures 3.8, 3.9, and 3.10 show the power distributions at EOC for the HEU, LEUm and LEUd cores, respectively.

The radial power distributions demonstrate the difference between the HEU and the two LEU cores. As is shown in Table 3.9, the maximum half-element power at SU increases from $427 \mathrm{~kW}$ to $449 \mathrm{~kW}$ when going from HEU to LEUm fuel (0.33 MW times relative power in Figures 3.5 and 3.6) and to $442 \mathrm{~kW}$ for the LEUd fuel. At EOC there is a decrease in the maximum halfelement power in going from HEU to the two LEU fuels. The location of the maximum power is also provided in the table.

There are two plena in the NBSR dividing the coolant flow between the six innermost fuel elements and the other 24 fuel elements. As is shown in Table 3.10, there is more than an 8\% increase in the power in the innermost six fuel elements (FEs) at SU when going from HEU to either LEU fuel and at EOC there is an 11\% increase, though the total power generated by the inner six FEs is smaller at EOC than at SU. This indicates that when converting from HEU to either LEU fuel, there is a net power shift from the perimeter of the core towards the inner portion of the core. 
Upper Core

$\begin{array}{llllllllllllll}\text { A } & \text { B } & \text { C } & \text { D } & \text { E } & \text { F } & \text { G } & \text { H } & \text { I } & \text { J } & \text { K } & \text { L } & \text { M }\end{array}$

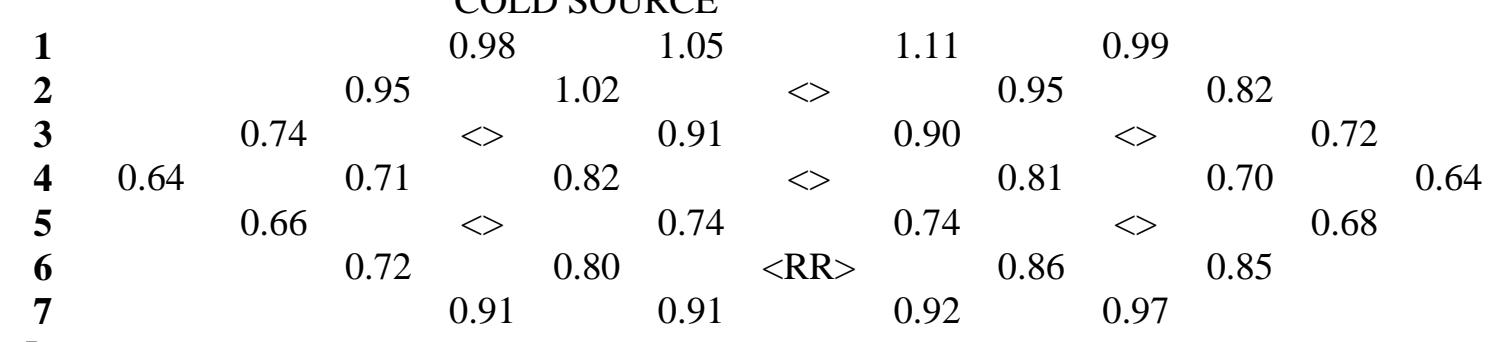

Lower core

$\begin{array}{lllllllllllll}\text { A } & \text { B } & \text { C } & \text { D } & \text { E } & \text { F } & \text { G } & \text { H } & \text { I } & \text { J } & \text { K } & \text { L } & \text { M }\end{array}$

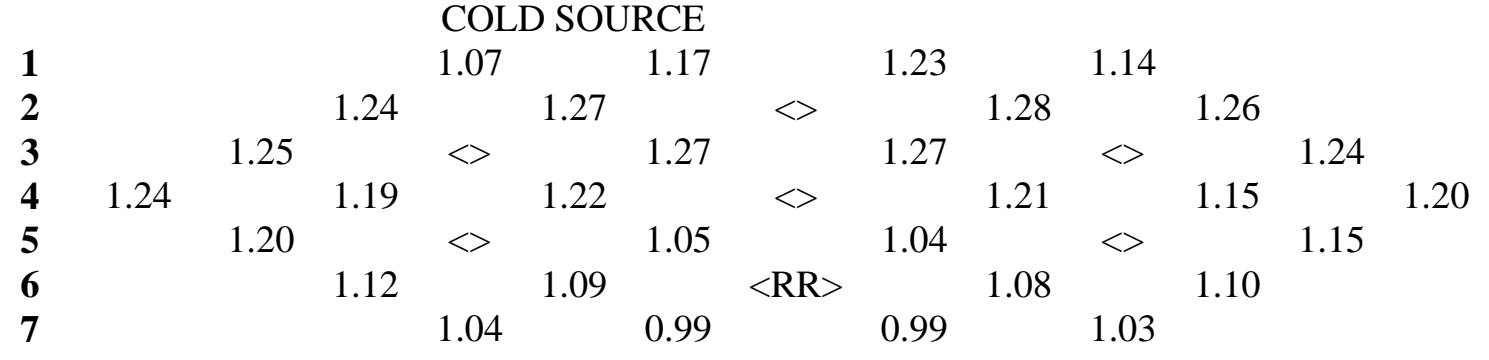

Figure 3.5 Radial Power Distribution for the Upper and Lower Halves of the HEU Core at SU

Upper Core
A
B C
$\begin{array}{lllllllllll}\mathbf{D} & \mathbf{E} & \mathbf{F} & \mathbf{G} & \mathbf{H} & \mathbf{I} & \mathbf{J} & \mathbf{K} & \mathbf{L} & \mathbf{M}\end{array}$ COLD SOURCE

$\begin{array}{lllllllllllllll}\mathbf{1} & & & & 0.90 & & 1.01 & & 1.05 & & 0.93 & & & \\ \mathbf{2} & & & 0.91 & & 1.01 & & <> & & 0.94 & & 0.78 & & \\ \mathbf{3} & & 0.71 & & <> & & 0.97 & & 0.96 & & <> & & 0.69 & \\ \mathbf{4} & 0.61 & & 0.73 & & 0.89 & & <> & & 0.89 & & 0.74 & & 0.62 \\ \mathbf{5} & & 0.66 & & <> & & 0.84 & & 0.85 & & <> & & 0.69 & \\ \mathbf{6} & & & 0.72 & & 0.84 & & <\mathrm{RR}> & & 0.91 & & 0.87 & & \\ \mathbf{7} & & & & 0.89 & & 0.91 & & 0.94 & & 0.96 & & & \end{array}$

Lower core

$\begin{array}{lllllllllllll}\text { A } & \text { B } & \text { C } & \text { D } & \text { E } & \text { F } & \text { G } & \text { H } & \text { I } & \text { J } & \text { K } & \text { L } & \text { M }\end{array}$

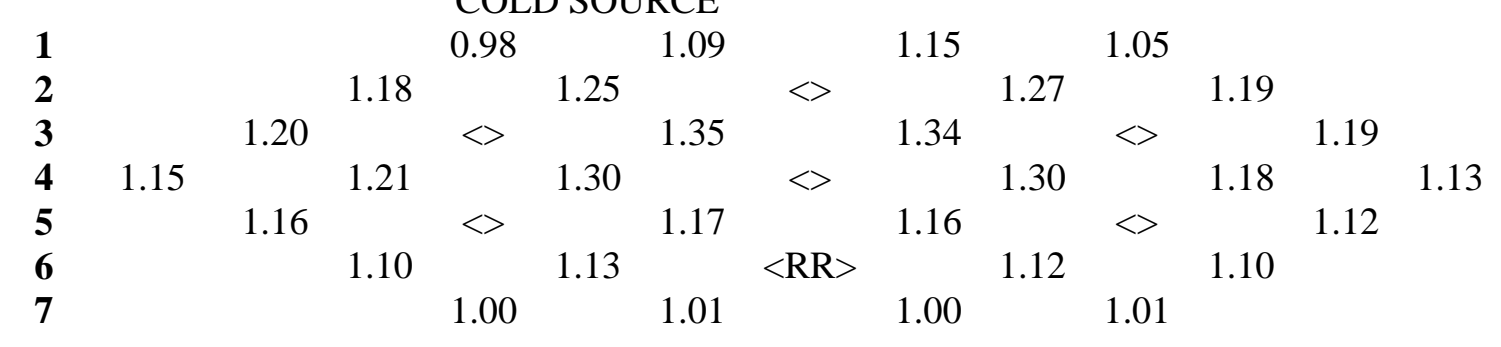

Figure 3.6 Radial Power Distribution for the Upper and Lower Halves of the LEUm Core at SU. 
Upper Core

$\begin{array}{lllllllllllll}\text { A } & \text { B } & \text { C } & \text { D } & \text { E } & \text { F } & \text { G } & \text { H } & \text { I } & \text { J } & \text { K } & \text { L } & \text { M }\end{array}$

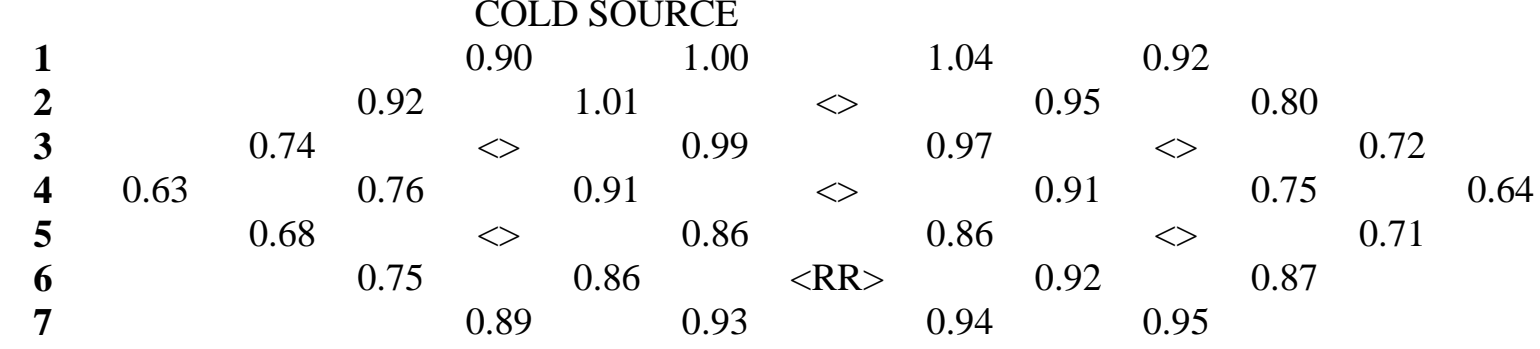

Lower core

$\begin{array}{lllllllllllll}\text { A } & \text { B } & \text { C } & \text { D } & \text { E } & \text { F } & \text { G } & \text { H } & \text { I } & \text { J } & \text { K } & \text { L } & \text { M }\end{array}$

\begin{tabular}{|c|c|c|c|c|c|c|c|c|c|c|c|c|}
\hline 1 & & & & 0.97 & 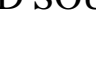 & 1.07 & & 1.13 & & 1.03 & & \\
\hline 2 & & & 1.16 & & 1.24 & & $<>$ & & 1.25 & & 1.17 & \\
\hline 3 & & 1.18 & & $<>$ & & 1.33 & & 1.33 & & $<>$ & & 1.17 \\
\hline 4 & 1.15 & & 1.20 & & 1.29 & & $<>$ & & 1.28 & & 1.17 & \\
\hline & & 1.16 & & $<>$ & & 1.17 & & 1.16 & & $<>$ & & 1.11 \\
\hline 6 & & & 1.10 & & 1.12 & & $<\mathrm{RR}>$ & & 1.11 & & 1.08 & \\
\hline 7 & & & & 1.00 & & 1.00 & & 1.00 & & 1.00 & & \\
\hline
\end{tabular}

Figure 3.7 Radial Power Distribution for the Upper and Lower Halves of the LEUd Core at SU.

Upper Core
A
B $\mathbf{D}$
COLD SOURCE
$\begin{array}{lllllll}\text { G } & \text { H } & \text { I } & \text { J } & \text { K } & \text { L } & \text { M }\end{array}$

C

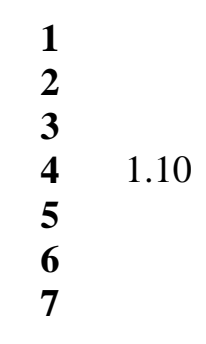

\begin{tabular}{cccccc} 
& \multicolumn{6}{c}{1.00} & & 1.11 & \\
1.09 & 1.08 & & 1.11 & & $<>$ \\
& 1.03 & $<$ & & 1.07 & \\
1.08 & & $<>$ & 1.04 & & $<$. \\
& 1.07 & & 1.02 & & $<\mathrm{RR}>$ \\
& & 1.08 & & 1.01 &
\end{tabular}

$1.18 \quad 1.11$

$1.07 \begin{array}{ll}1.14 & <1.16\end{array}$ 1.16 $\begin{array}{lllllll}0.91 & 1.04 & & 1.03 & & 1.11 \\ & & <> & & 1.03 & \\ & 1.01 & & 1.02 & & \end{array}$

Lower core
A
B C
C D
G $\quad \mathbf{H}$
$\begin{array}{llllll}\mathbf{H} & \mathbf{I} & \mathbf{J} & \mathbf{K} & \mathbf{L} & \mathbf{M}\end{array}$

$\mathbf{D}$
COLD SOURCE

$\begin{array}{ll}\mathbf{1} & \\ \mathbf{2} & \\ \mathbf{3} & \\ \mathbf{4} & 1.05 \\ \mathbf{5} & \\ \mathbf{6} & \\ \mathbf{7} & \end{array}$

\begin{tabular}{|c|c|c|c|c|c|c|c|c|c|c|c|}
\hline & & CUI & 50 & KLE & & & & & & & \\
\hline & & 0.85 & & 0.93 & & 0.97 & & 0.91 & & & \\
\hline & 0.99 & & 0.98 & & $<>$ & & 1.00 & & 1.02 & & \\
\hline 1.02 & & $<>$ & & 0.96 & & 0.97 & & $<>$ & & 1.03 & \\
\hline & 0.96 & & 0.94 & & $<>$ & & 0.92 & & 0.93 & & 1.02 \\
\hline 1.01 & & $<>$ & & 0.82 & & 0.81 & & $<>$ & & 0.96 & \\
\hline & 0.94 & & 0.90 & & $<\mathrm{RR}>$ & & 0.88 & & 0.92 & & \\
\hline & & 0.90 & & 0.87 & & 0.85 & & 0.89 & & & \\
\hline
\end{tabular}

Figure 3.8 Radial Power Distribution for the Upper and Lower Halves of the HEU Core at EOC. 
Upper Core
$\begin{array}{lllllllllllll}\text { A } & \text { B } & \text { C } & \text { D } & \text { E } & \text { F } & \text { G } & \text { H } & \text { I } & \text { J } & \text { K } & \text { L } & \text { M }\end{array}$ COLD SOURCE

\begin{tabular}{|c|c|c|c|c|c|c|c|c|c|c|c|c|c|}
\hline & & & & & & & & & & & & & \\
\hline 1 & & & & 0.93 & & 1.04 & & 1.09 & & 1.02 & & & \\
\hline 2 & & & 1.04 & & 1.11 & & $<>$ & & 1.13 & & 1.09 & & \\
\hline 3 & & 1.04 & & $<>$ & & 1.15 & & 1.15 & & $<>$ & & 1.10 & \\
\hline 4 & 1.02 & & 1.06 & & 1.14 & & $<>$ & & 1.14 & & 1.05 & & 1.03 \\
\hline 5 & & 1.05 & & $<>$ & & 1.05 & & 1.04 & & $<>$ & & 1.01 & \\
\hline 6 & & & 1.05 & & 1.06 & & $<\mathrm{RR}>$ & & 1.05 & & 1.01 & & \\
\hline 7 & & & & 1.03 & & 1.02 & & 1.01 & & 1.01 & & & \\
\hline
\end{tabular}

Lower core
A
B
C $\quad$ D $\quad$ E $\quad$ F
G $\quad$ H
I $\mathbf{J} \quad \mathbf{K}$
K $\quad \mathbf{L} \quad \mathbf{M}$ COLD SOURCE

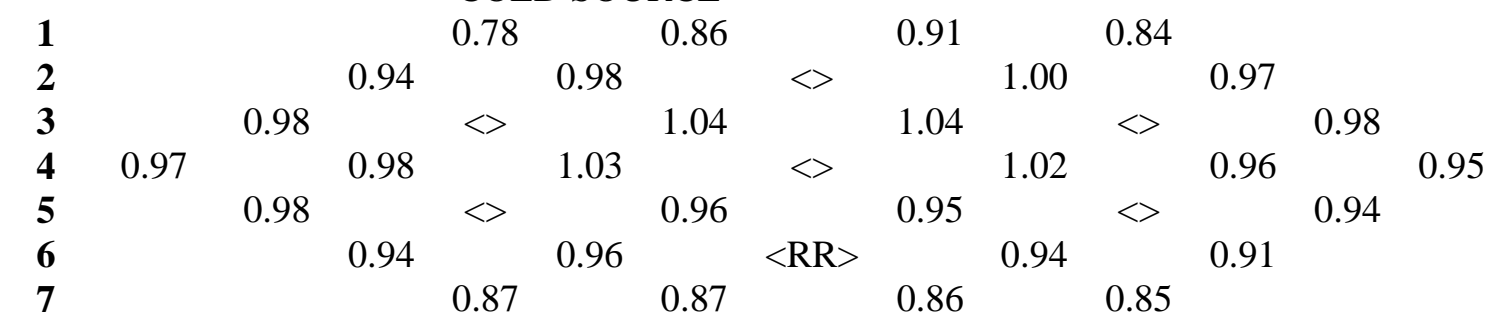

Figure 3.9 Radial Power Distribution for the Upper and Lower Halves of the LEUm Core at EOC.

Upper Core
A
B C

\section{EOC.}

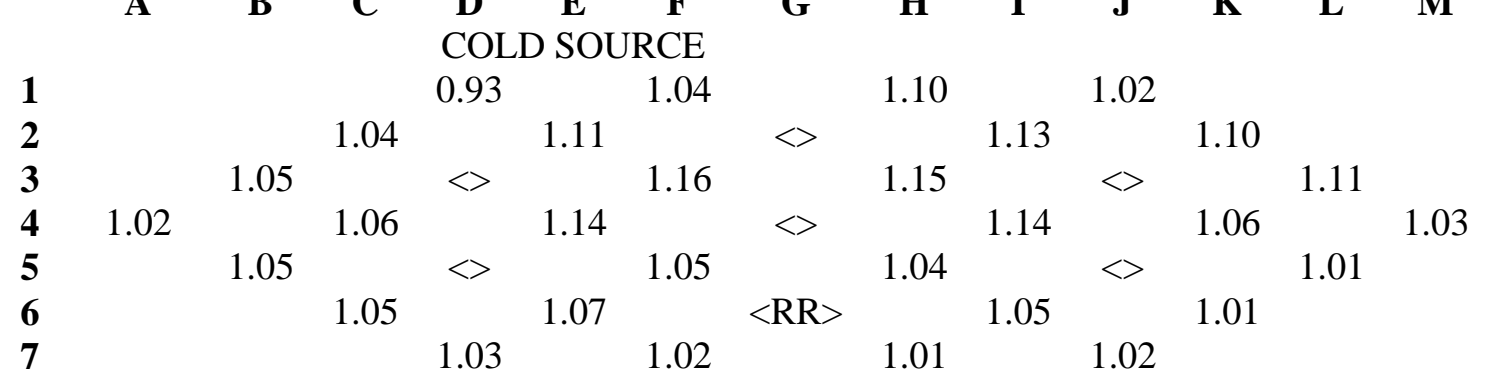

Lower core
A
B C
$\underset{\text { COLD }}{\mathbf{E}} \underset{\text { SOURCE }}{\mathbf{F}}$
$\begin{array}{lllll}\text { G } & \text { H } & \text { I } & \text { J } & \text { K }\end{array}$
L $\quad$ M

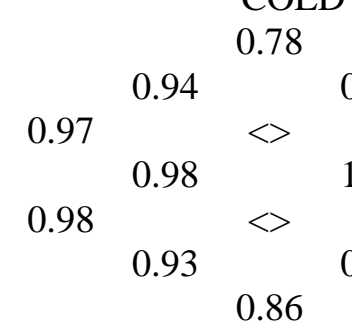
$0.78 \quad 0.86$
$0.91 \quad 0.84$
$\begin{array}{lllllll}0.98 & <> & & 1.00 & & 0.97\end{array}$
$1.04<>$
$\begin{array}{llllll}1.04 & & < & 0.97 & & \\ & & & 0.98 & \\ & 1.02 & & 0.96 & & 0.95\end{array}$
1
2
3
4
$\begin{array}{ll}4 & 0.97\end{array}$
5
6

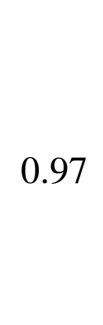

Figure 3.10 Radial Power Distribution for the Upper and Lower Halves of the LEUd Core at EOC. 
Table 3.9 Highest Half-Element Power (kW)

\begin{tabular}{|c|c|c|c|c|}
\hline & \multicolumn{2}{|c|}{ SU } & \multicolumn{2}{c|}{ EOC } \\
\hline HEU & I2 Lower & 427 & H1 Upper & 393 \\
\hline LEUm & F3 Lower & 449 & H3 Upper & 385 \\
\hline LEUd & F3 Lower & 442 & F3 Upper & 386 \\
\hline
\end{tabular}

Table 3.10 Power (MW) Generated by the Inner Plenum FEs

vs. the Outer Plenum FEs

\begin{tabular}{|l|c|c|c|c|c|c|c|c|c|c|}
\hline & \multicolumn{4}{|c|}{ SU } & \multicolumn{5}{|c|}{ EOC } \\
\hline & HEU & LEUm & $\begin{array}{c}\Delta(\%) \\
\text { HEU } \\
\text { to } \\
\text { LEUm }\end{array}$ & LEUd & $\begin{array}{c}\Delta(\%) \\
\text { HEU to } \\
\text { LEUd }\end{array}$ & HEU & LEUm & $\begin{array}{c}\Delta(\%) \\
\text { HEU } \\
\text { to } \\
\text { LEUm }\end{array}$ & LEUd & $\begin{array}{c}\Delta(\%) \\
\text { HEU to } \\
\text { LEUd }\end{array}$ \\
\hline $\begin{array}{l}\text { Outer } \\
24\end{array}$ & 16.00 & 15.64 & -2.10 & 15.65 & -2.16 & 16.18 & 15.76 & -2.60 & 15.77 & -2.55 \\
\hline Inner 6 & 4.00 & 4.34 & 8.40 & 4.35 & 8.65 & 3.82 & 4.24 & 11.10 & 4.23 & 10.80 \\
\hline
\end{tabular}

At SU there is more power generated in the lower half of the core than there is in the upper half of the core. This is due to the shim arms suppressing the power in the upper half of the core at SU. Because there is more power generated in the lower half of the core than there is in the upper half of the core starting at SU, the burnup is initially reduced in the upper half of the core. By the time the shim arms are swung out of the core and the EOC is approached the power is shifted to the upper half of the core as is demonstrated in Table 3.11.

A model of the NBSR was developed where the fuel elements were divided into $2 \times 2 \mathrm{~cm}$ (nominally) squares. The number of fissions, which is proportional to the local power density, was calculated for each square. Thermal-hydraulic analyses are to be performed using these three-dimensional power distributions to ensure the reactor can be safely operated with either LEU fuel at all points in the fuel cycle.

Table 3.11 Power (MW) Generated in the Upper Half vs. the Lower Half

\begin{tabular}{|l|c|c|c|c|c|c|c|c|c|c|}
\multicolumn{10}{c|}{ of the Core } \\
\hline & HEU & LEUm & $\begin{array}{c}\Delta(\%) \\
\text { HEU } \\
\text { to } \\
\text { LEUm }\end{array}$ & LEUd & $\begin{array}{c}\Delta(\%) \\
\text { HEU } \\
\text { to } \\
\text { LEUd }\end{array}$ & HEU & LEUm & $\begin{array}{c}\Delta(\%) \\
\text { HEU } \\
\text { to } \\
\text { LEUm }\end{array}$ & LEUd & $\begin{array}{c}\Delta(\%) \\
\text { HEU } \\
\text { to } \\
\text { LEUd }\end{array}$ \\
\hline Upper & 8.4 & 8.5 & 0.9 & 8.6 & 2.2 & 10.6 & 10.6 & -0.2 & 10.6 & -0.1 \\
\hline Lower & 11.6 & 11.5 & -0.6 & 11.4 & -1.6 & 9.4 & 9.4 & 0.2 & 9.4 & 0.01 \\
\hline
\end{tabular}




\subsection{Figure-of-Merit for the Neutron Beams}

The main purpose of the NBSR is to provide neutron beams for scientific research. In order to assess the impact of the conversion on neutron beam performance, the neutron flux was calculated at four locations in the existing cold neutron source (CNS) and one location in each of beam tubes 1, 4, 7, and 9.The fluxes were averaged with the locations in the CNS given double weight. A figure-of-merit (FOM) was defined as the ratio (in \%) of the resulting average with LEU fuel to that with HEU fuel. The FOM for the LEUm fuel at SU is $92 \%$ and at EOC is $90 \%$ and for the LEUd fuel it is $91 \%$ at both SU and EOC, consistent with the LEUm fuel. Hence, the conversion to LEU represents approximately a $10 \%$ decline in neutron beam performance for experimenters.

\subsection{Effect of Dropping the Coolant to the Dump Level}

The NBSR has a pipe, referred to as the moderator dump, whose entrance is just above the fueled portion of the core. If an emergency situation requires it, the pipe can be used to drain the coolant to that dump level leaving the core with no upper reflector. The lack of an upper reflector should result in the reactor becoming subcritical. The NBSR model was modified so that the coolant above the core could be changed as is shown in Figure 3.11. In this figure the area above the fueled portion of the core is devoid of coolant. Calculations of the $\mathrm{k}_{\mathrm{eff}}$ when the coolant is lowered to the dump level were performed for the case that the shim arms and regulating rod were fully withdrawn. These results are shown in Table 3.12 and demonstrate that the NBSR can be kept subcritical under all conditions if the coolant were to be lowered to the dump level.

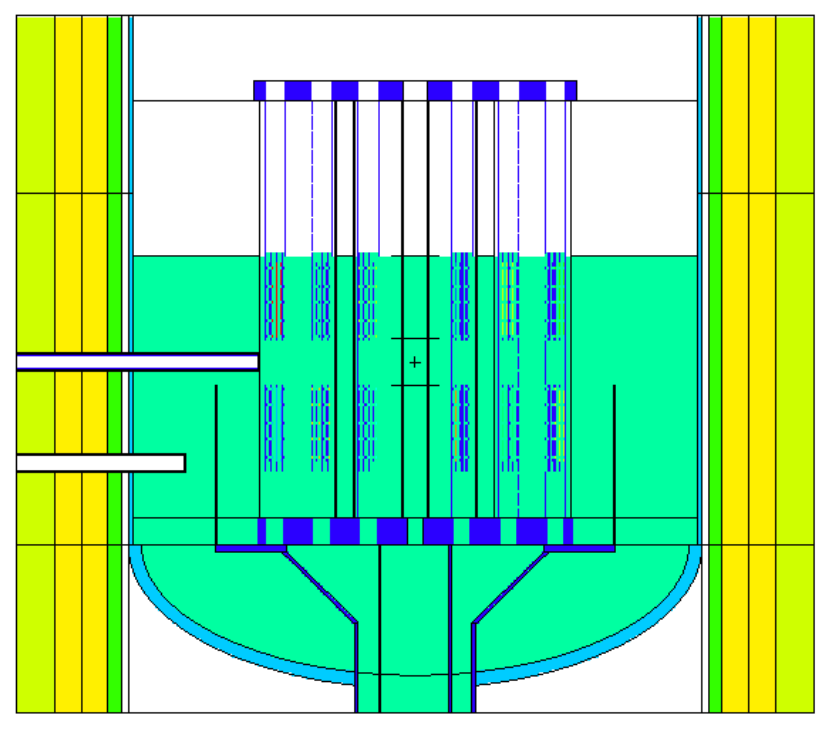

Figure 3.11 Vertical Section of the NBSR with the Coolant Dropped to the Dump Level 
Table 3.12 Value of $\mathbf{k}_{\text {eff }}$ when the Coolant is Lowered to the Dump Level

\begin{tabular}{|l|c|c|c|}
\hline & HEU & LEUm & LEUd \\
\hline SU & $0.98572 \pm 0.00044$ & $0.98491 \pm 0.00029$ & $0.98359 \pm 0.00029$ \\
\hline EOC & $0.91241 \pm 0.00029$ & $0.92150 \pm 0.00028$ & $0.92445 \pm 0.00028$ \\
\hline
\end{tabular}

\subsection{Beam Tube Flooding}

Beam tube flooding is hypothesized to occur if a $\mathrm{D}_{2} \mathrm{O}$ cooled experiment in a beam tube were to leak, or a crack were to occur in a beam tube, a thimble, or the cold neutron source. Such an event would allow $\mathrm{D}_{2} \mathrm{O}$ to enter areas that are normally filled with air or vacuum and introduce a positive reactivity. The three situations calculated for the SAR are reproduced in Table 3.13. As can be seen from the table, the reactivity added is less than the $0.5 \% \Delta \mathrm{k} / \mathrm{k}$ used to analyze the maximum reactivity insertion accident in the SAR.

Table 3.13 Reactivity Insertion $(\% \Delta \mathrm{k} / \mathrm{k})$ from Flooding the Beam Tubes

\begin{tabular}{|l|c|c|c|c|c|c|}
\hline \multirow{2}{*}{} & \multicolumn{2}{|c|}{ SU } & & \multicolumn{2}{c|}{ EOC } & \\
\cline { 2 - 7 } & HEU & LEUm & LEUd & HEU & LEUm & LEUd \\
\hline CNS Flooded & $0.24 \%$ & $0.15 \%$ & $0.25 \%$ & $0.25 \%$ & $0.15 \%$ & $0.28 \%$ \\
\hline Average Radial Beam Tube & $0.17 \%$ & $0.17 \%$ & $0.17 \%$ & $0.18 \%$ & $0.17 \%$ & $0.17 \%$ \\
\hline One Tangential Beam Tube & $0.27 \%$ & $0.26 \%$ & 0.30 & $0.20 \%$ & $0.26 \%$ & $0.21 \%$ \\
\hline
\end{tabular}

\subsection{Light Water Ingress}

The NBSR is a $\mathrm{D}_{2} \mathrm{O}$ cooled and moderated system. The $\mathrm{D}_{2} \mathrm{O}$ is $99.97 \%$ pure. Any light water contamination would have a negative effect on the operability of the NBSR which is shown in Figures 3.12 and 3.13 for the SU and EOC states. 


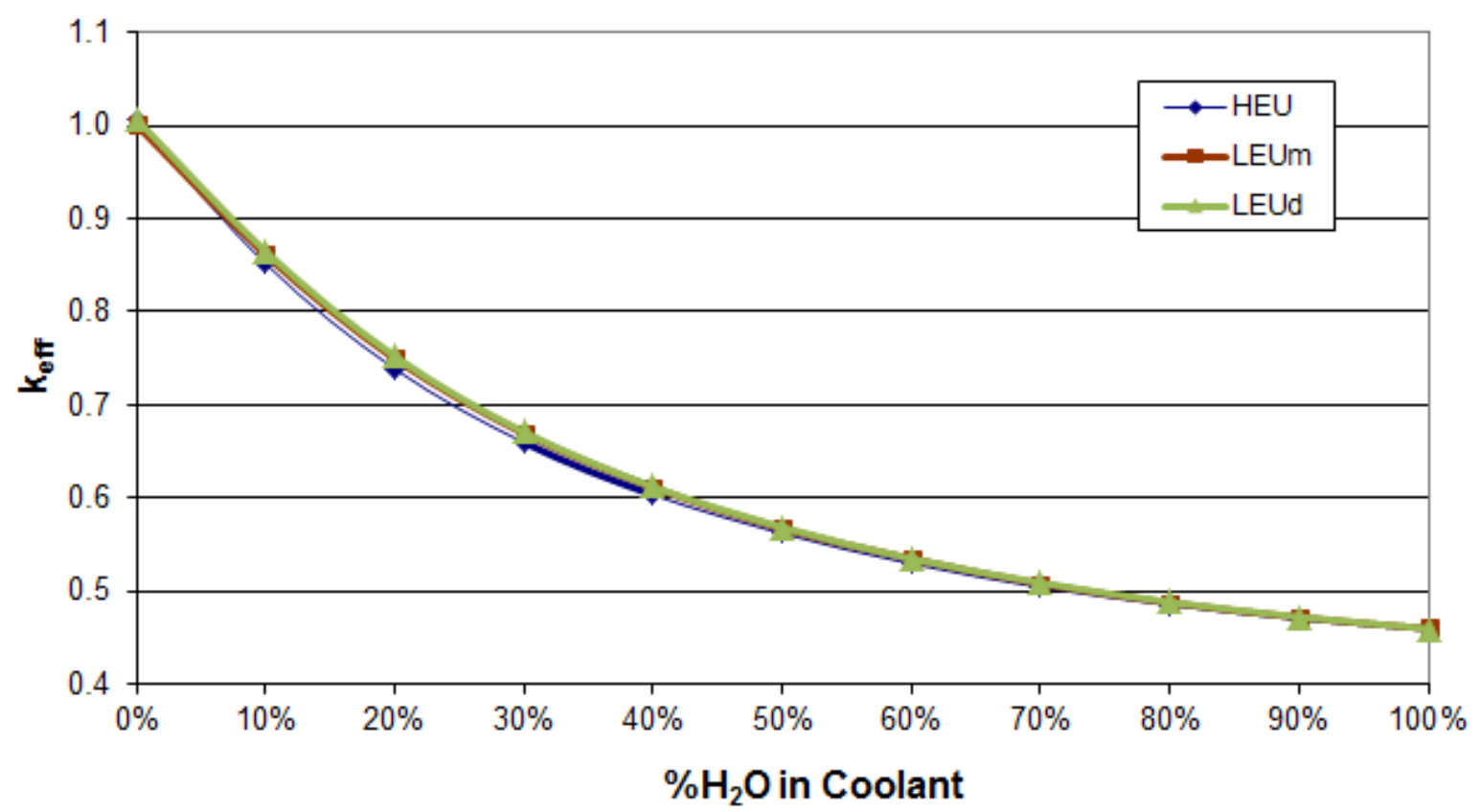

Figure 3.12 Effect of Light Water Ingress on the Value of $\mathbf{k}_{\text {eff }}$ at $\mathrm{SU}$

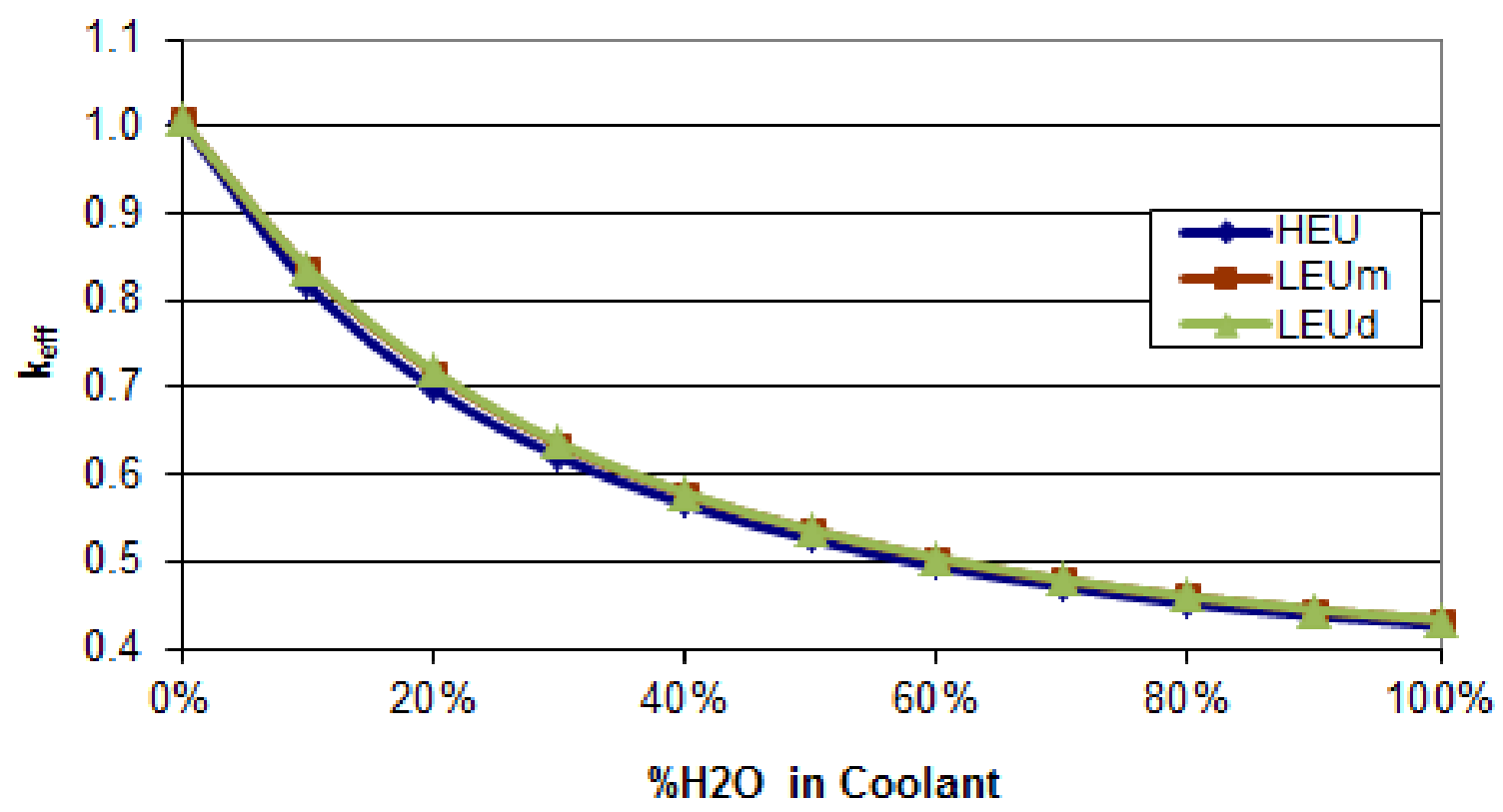

Figure 3.13 Effect of Light Water Ingress on the Value of $\mathbf{k}_{\text {eff }}$ at EOC 


\subsection{Fuel Misloading Accident}

The fuel misloading accident is analyzed assuming a fresh, unirradiated fuel element is inserted into an incorrect location. This might cause a power level in that fuel element which could be unacceptable in terms of thermal limits. In order to perform this analysis, one fuel element was placed in each position in the core and the fuel element that should have been placed in that location is placed in the A4 position (one of the four positions for fresh fuel element). The radial power distributions were calculated at SU, the limiting condition. The half-element with the maximum relative power was determined and the location and relative power are given in Table 3.14. The first column is the location in which the fresh fuel element was placed, the second, fourth, and sixth columns show the location which exhibited the highest relative power and the third, fifth, and seventh columns show the relative power (unity represents $20 \mathrm{MW}$ / 60 materials) in the location.

For the HEU fuel the highest power occurred when the fresh fuel element was placed in the F3 location and for both of the LEU fuels the highest power occurred in the H3 location and for LEUm fuel also in F3 (as marked in red in the table). Figure 3.14 shows the radial power distribution for the fresh HEU fuel element placed in the F3 position and Figure 3.15 shows the radial power distribution for the fresh LEUm fuel element placed in the H3 position and Figure 3.16 shows the radial power distribution for the fresh LEUd fuel element placed in the H3 position. 
Table 3.14 Maximum Relative Power (RP) in the Lower Half-Element for a Misloaded FE at $\mathrm{SU}$

\begin{tabular}{|l|c|c|c|c|c|c|}
\hline & \multicolumn{2}{|c|}{ HEU } & \multicolumn{2}{c|}{ LEUm } & \multicolumn{2}{c|}{ LEUd } \\
\hline & Max FE & Max RP & Max FE & Max RP & Max FE & Max RP \\
\hline Normal & F3 & 1.28 & H3 & 1.35 & F3 & 1.33 \\
\hline $\begin{array}{l}\text { Swap fresh FE } \\
\text { with: }\end{array}$ & & & & & & \\
\hline F1 & I2 & 1.29 & F3 & 1.35 & H3 & 1.33 \\
\hline B3 & B3 & 1.39 & H3 & 1.35 & F2 & 1.32 \\
\hline C6 & C6 & 1.34 & H3 & 1.34 & H3 & 1.32 \\
\hline E2 & E2 & 1.66 & E2 & 1.54 & E2 & 1.51 \\
\hline E6 & E6 & 1.56 & E6 & 1.48 & E6 & 1.47 \\
\hline E4 & E4 & 1.91 & E4 & 1.81 & E4 & 1.77 \\
\hline D7 & H3 & 1.27 & H3 & 1.35 & H3 & 1.33 \\
\hline C2 & C2 & 1.37 & F3 & 1.35 & H3 & 1.33 \\
\hline B5 & B5 & 1.43 & B5 & 1.36 & F4 & 1.32 \\
\hline F7 & F7 & 1.30 & H3 & 1.32 & H4 & 1.31 \\
\hline C4 & C4 & 1.68 & C4 & 1.56 & C4 & 1.51 \\
\hline F3 & F3 & 1.93 & F3 & 1.83 & F3 & 1.81 \\
\hline F5 & F5 & 1.87 & F5 & 1.80 & F5 & 1.75 \\
\hline H1 & I2 & 1.30 & H3 & 1.35 & H3 & 1.33 \\
\hline L3 & L3 & 1.38 & F3 & 1.36 & H3 & 1.34 \\
\hline K6 & K6 & 1.34 & H3 & 1.35 & H3 & 1.33 \\
\hline I2 & I2 & 1.66 & I2 & 1.54 & I2 & 1.55 \\
\hline I6 & I6 & 1.55 & I6 & 1.48 & I6 & 1.48 \\
\hline I4 & I4 & 1.89 & I4 & 1.79 & I4 & 1.82 \\
\hline J7 & H3 & 1.27 & F3 & 1.34 & H3 & 1.33 \\
\hline K2 & K2 & 1.39 & H3 & 1.35 & H3 & 1.33 \\
\hline L5 & L5 & 1.38 & H3 & 1.35 & H3 & 1.34 \\
\hline H7 & H7 & 1.33 & F3 & 1.33 & H3 & 1.32 \\
\hline K4 & K4 & 1.62 & K4 & 1.53 & K4 & 1.53 \\
\hline H3 & H3 & 1.92 & H3 & 1.83 & H3 & 1.83 \\
\hline H5 & H5 & 1.87 & H5 & 1.79 & H5 & 1.77 \\
\hline
\end{tabular}


Upper Core

$\begin{array}{lllllllllllll}\text { A } & \text { B } & \text { C } & \text { D } & \mathbf{E} & \mathbf{F} & \text { G } & \text { H } & \text { I } & \text { J } & \text { K } & \text { L } & \text { M }\end{array}$

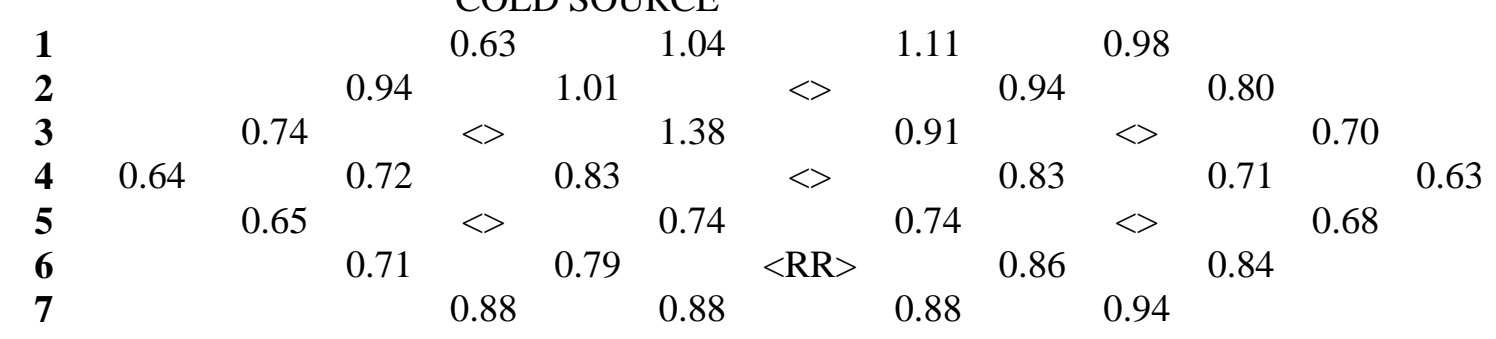

$\begin{array}{ccccccccccccc}\text { Lower core } & & & & & & & & & & & & \end{array}$ $\begin{array}{lllllllllllll}\mathbf{A} & \mathbf{B} & \mathbf{C} & \mathbf{D} & \mathbf{E} & \mathbf{F} & \mathbf{G} & \mathbf{H} & \mathbf{I} & \mathbf{J} & \mathbf{K} & \mathbf{L} & \mathbf{M}\end{array}$

\begin{tabular}{|c|c|c|c|c|c|c|c|c|c|c|c|c|c|}
\hline 1 & & & & 0.70 & & 1.16 & & 1.22 & & 1.12 & & & \\
\hline 2 & & & 1.22 & & 1.28 & & $<>$ & & 1.29 & & 1.23 & & \\
\hline 3 & & 1.24 & & $<>$ & & 1.93 & & 1.30 & & $<>$ & & 1.22 & \\
\hline 4 & 1.25 & & 1.22 & & 1.24 & & $<>$ & & 1.21 & & 1.15 & & 1.17 \\
\hline 5 & & 1.18 & & $<>$ & & 1.06 & & 1.04 & & $<>$ & & 1.13 & \\
\hline 6 & & & 1.09 & & 1.07 & & $<\mathrm{RR}>$ & & 1.06 & & 1.08 & & \\
\hline 7 & & & & 1.02 & & 0.97 & & 0.97 & & 1.02 & & & \\
\hline
\end{tabular}

Figure 3.14 Radial Power Distribution when the Fresh HEU Fuel Element is Placed in the F3 Position

Upper Core
A
B C
$\begin{array}{lllllllllll}\mathbf{D} & \mathbf{E} & \mathbf{F} & \mathbf{G} & \mathbf{H} & \mathbf{I} & \mathbf{J} & \mathbf{K} & \mathbf{L} & \mathbf{M}\end{array}$ COLD SOURCE . 


\begin{tabular}{ccccccccccccccc}
$\begin{array}{c}\text { Upper Core } \\
\text { A }\end{array}$ & $\mathbf{B}$ & $\mathbf{C}$ & $\mathbf{D}$ & $\mathbf{E}$ & $\mathbf{F}$ & $\mathbf{G}$ & $\mathbf{H}$ & $\mathbf{I}$ & $\mathbf{J}$ & $\mathbf{K}$ & $\mathbf{L}$ & $\mathbf{M}$ \\
& & & & \multicolumn{2}{c}{ COLD SOURCE } & & & & & & & \\
$\mathbf{1}$ & & & & 0.88 & & 1.02 & & 1.09 & & 0.97 & & & \\
$\mathbf{2}$ & & & 0.89 & & 1.02 & & $<>$ & & 1.00 & & 0.84 & & \\
$\mathbf{3}$ & & 0.70 & & $<>$ & & 0.99 & & 1.35 & & $<>$ & & 0.74 & \\
$\mathbf{4}$ & 0.43 & & 0.71 & & 0.90 & & $<>$ & & 0.94 & & 0.78 & & 0.65 \\
$\mathbf{5}$ & & 0.63 & & $<>$ & & 0.84 & & 0.86 & & $<>$ & & 0.71 & \\
$\mathbf{6}$ & & & 0.71 & & 0.83 & & $<\mathrm{RR}>$ & & 0.90 & & 0.86 & & \\
$\mathbf{7}$ & & & & 0.84 & & 0.90 & & 0.91 & & 0.92 & & &
\end{tabular}

SU

Lower core

$\begin{array}{lllllllllllll}\text { A } & \text { B } & \text { C } & \text { D } & \text { E } & \text { F } & \text { G } & \text { H } & \text { I } & \text { J } & \text { K } & \text { L } & \text { M }\end{array}$

\begin{tabular}{|c|c|c|c|c|c|c|c|c|c|c|c|c|c|}
\hline 1 & & & & 0.95 & & 1.10 & & 1.18 & & 1.08 & & & \\
\hline 2 & & & 1.12 & & 1.24 & & $<>$ & & 1.31 & & 1.23 & & \\
\hline 3 & & 1.11 & & $<>$ & & 1.36 & & 1.83 & & $<>$ & & 1.21 & \\
\hline 4 & 0.79 & & 1.14 & & 1.28 & & $<>$ & & 1.32 & & 1.19 & & 1.14 \\
\hline 5 & & 1.07 & & $<>$ & & 1.14 & & 1.16 & & $<>$ & & 1.13 & \\
\hline 6 & & & 1.03 & & 1.07 & & $<\mathrm{RR}>$ & & 1.10 & & 1.08 & & \\
\hline 7 & & & & 0.94 & & 0.96 & & 0.97 & & 0.98 & & & \\
\hline
\end{tabular}

Figure 3.16 Radial Power Distribution when the Fresh LEUd Fuel Element is Placed in the H3 Position 


\section{CONCLUSIONS}

The MCNP6 computer code with the BURN option was used to calculate the equilibrium fuel composition for the NBSR when fueled with a U7Mo dispersion fuel. The results of the calculations were compared to earlier results for HEU (the current fuel) and LEUm (U10Mo monolithic) fuels. Neutronic parameters needed for safety analyses and to evaluate the flux for experiments were calculated at startup and end-of-cycle. The results showed differences between the HEU and both LEU cores but similar values comparing the LEUm and LEUd cores. The results mean no significant changes in the safety analysis for the converted core if the core were to be converted to LEUm or LEUd. The most significant change in the performance of the NBSR because of conversion is in the neutron beams to be provided to experimentalists. Indeed, calculations of the figure-of-merit for providing neutrons shows a decrease in performance of approximately $10 \%$ throughout the cycle regardless of the LEU fuel selected.

The calculated delayed neutron fraction decreased slightly in going from HEU to either LEU fuel and this is consistent with the additional amount of fissions from ${ }^{239} \mathrm{Pu}$ that take place in the LEU core. Neutron lifetime calculations showed some anomalies but are consistent with the large uncertainty associated with the calculation. Reactivity coefficients for moderator temperature and void changes did not change significantly nor did the reactivity effect of dropping the coolant to the dump level, beam tube flooding, or light water ingress. Total shim arm worth was not significantly changed and since both types of cores would have to have similar excess reactivity to run the same fuel cycle length, both cores showed similar shutdown margin (calculated with each of the four shim arms assumed out of the core).

Power distributions were also calculated through a fuel cycle. A comparison of the power in half-element sections of fuel elements showed significant differences in that the HEU core had its highest fuel element powers at the core periphery whereas either LEU core has the power peaking in the center. This is detrimental to providing neutrons to experimentalists through the various beam tubes. There was also an increase in the maximum half-element power in the LEU core at startup relative to that for the HEU core. The effect on the thermal-hydraulics has been checked in preliminary calculations that are ongoing and has been found to be not limiting. The effect on power of a misloaded fuel element has been calculated to be greatest in the HEU core where previously it had been shown to not reduce safety margin significantly. 


\section{REFERENCES}

1. A.L. Hanson and D.J. Diamond, "Calculation of Design Parameters for an Equilibrium LEU Core in the NBSR”, BNL-96386-2011-IR, Brookhaven National Laboratory, September 29, 2011.

2. NIST, "Safety Analysis Report (SAR) for License Renewal for the National Institute of Standards and Technology Reactor - NBSR; NBSR 14, Rev 4," National Institute of Standards and Technology (NIST), 2010.

3. Hanson, A., and Diamond, D., "A Neutronics Methodology for the NIST Research Reactor Based on MCNPX," in 19th International Conference on Nuclear Engineering (ICONE19), Chiba, Japan, May 16-19, 2011.

4. D.I. Poston and H.R. Trellue, MONTEBURNS, Version 2.0, Los Alamos National Laboratory, updated Dec. 2, 2002.

5. “MCNP - A General Monte Carlo N-Particle Transport Code, Version 5,” LA-UR-03-1987, Los Alamos National Laboratory, April 24, 2003.

6. S. Ludwig, "Revision to ORIGEN2 - Version 2.2,” Oak Ridge National Laboratory, May 23, 2002.

7. D.B. Pelowitz, Ed., “MCNPX User’s Manual version 2.6.0,” LA-CP-07-1473, Los Alamos National Laboratory, April, 2008.

8. W.B Wilson, T.R. England, M. Herman, R.E. MacFarland, and D.W. Muir, “Cinder'90 Code for Transmutation Calculations”, LA-UR-97-2655, Los Alamos National Laboratory, 1997.

9 D.B. Pelowitz, Ed., "MCNP6 ${ }^{\mathrm{TM}}$ User’s Manual”, LA-CP-11-01708, Los Alamos National Laboratory, December, 2012.

10 A.L. Hanson and D.J. Diamond, "Calculation of Inventories, Power Distributions and Neutronic Parameters for the NBSR Using MCNPX," Presented at the TRTR/IGORR Joint Meeting, Knoxville, TN, September 19-23, 2010.

11 D. Wachs, private conversation, Idaho National Laboratory, Dec., 2013 and Feb. 2014.

12 J. Bess, "September 2011 Status Update for the NRAD Reactor Benchmark Models," Presented at the TRTR Meeting, Idaho Falls, ID, September 13-15, 2011.

13 J. Wang, and W.D. Reece, "Comparison of Different Numerical Methods Used in Delayed Neutron Decay Parameters Estimation,” Nuclear Science and Engineering, 167, 2011.

14 NIST, "Technical Specifications for the NIST Test Reactor (NBSR)," Appendix A to License No. TR-5, National Institute of Standards and Technology (NIST), 2010. 
15. A.L. Hanson, D.J. Diamond, and R.E. Williams, "Depletion of the Cadmium Shim Arms in the NBSR”, memo to files, Brookhaven National Laboratory, November, 2005.

16. A.L. Hanson and D.J. Diamond, "Depletion of the Cadmium Shim Arms in the NBSR for the COMP7 LEU Core”, memo to files, Brookhaven National Laboratory, July 28, 2009. 